\title{
Fit, Style, and the Portability of Managerial Talent*
}

\author{
Yuk Ying Chang, Sudipto Dasgupta, Jie Gan ${ }^{1,2}$
}

\begin{abstract}
How portable are top management skills? Should (and do) firms care about firmmanager fit when they hire new managers? How is fit related to managerial "style"? We hypothesize that if firms and managers are matched with each other on the basis of fit on multiple dimensions, then firms that employ the same manager at adjacent points of time should have similar characteristics. We find strong evidence that firms that employ the same manager sort on a number of characteristics. Our empirical design ensures that these results are not explained by managerial style, or by moves among firms of similar size, or within the same industry. We construct a measure for the quality of fit. We find that a worse fit leads to less positive stock price reaction to the announcement of managerial appointments, lower managerial pay, and shorter tenure for the manager, suggesting that management skills do not necessarily transfer from one firm environment to another. We also find evidence that when the firm and the manager do not fit well, managers influence several firm-specific variables, consistent with managerial style.
\end{abstract}

JEL Classification: G30, G32, J24

Keywords: Managerial labor market, Transferrable managerial skills, Job assignment, Managerial style

\footnotetext{
* We thank Alex Edmans, Dirk Jenter, Mike Lemmon, Ernst Maug, Peter MacKay, Kasper Nielsen, Rik Sen, Jeremy Stein, and seminar participants at HKUST's brown bag seminar and the 2011 Asian Finance Association meetings, where early versions of the paper were presented under a different title. All errors are our own.

${ }^{1}$ Chang is from Massey University. Email: y.chang@massey.ac.nz. Dasgupta is from Hong Kong University of Science and Technology. Email: dasgupta@ust.hk. Gan is from the Hong Kong University of Science and Technology and the Cheung Kong Graduate School of Business. Email: igan@ckgsb.edu.cn.

${ }^{2}$ Dasgupta acknowledges financial support for this research from Hong Kong's Research Grants Council (project \# 640409). Gan acknowledges financial support from Hong Kong Research Grants Council (Project \# 641408).
} 


\title{
Fit, Style, and the Portability of Managerial Talent
}

\begin{abstract}
How portable are top management skills? Should (and do) firms care about firmmanager fit when they hire new managers? How is fit related to managerial "style"? We hypothesize that if firms and managers are matched with each other on the basis of fit on multiple dimensions, then firms that employ the same manager at adjacent points of time should have similar characteristics. We find strong evidence that firms that employ the same manager sort on a number of characteristics. Our empirical design ensures that these results are not explained by managerial style, or by moves among firms of similar size, or within the same industry. We construct a measure for the quality of fit. We find that a worse fit leads to less positive stock price reaction to the announcement of managerial appointments, lower managerial pay, and shorter tenure for the manager, suggesting that management skills do not necessarily transfer from one firm environment to another. We also find evidence that when the firm and the manager do not fit well, managers influence several firm-specific variables, consistent with managerial style.
\end{abstract}


There is now a growing literature documenting the importance of the $\mathrm{CEO}$ - that is, the person who leads the firm - for firm value, performance, investment, and even financial structure. For example, we have evidence that firm performance declines and the stock market reacts negatively after sudden deaths of CEOs (Bennedsen, Pérez-González and Wolfenzon (2008), Nguyen and Nielsen (2010)). ${ }^{3}$ Bertrand and Schoar (2003) argue that CEOs have unique management styles and leave their imprints on the firms they manage. The talent assignment models that are successful in explaining the rapid rise in CEO pay over the last four decades also build on the heterogeneity of CEO talent (Terviö (2008), Gabaix and Landier (2008)).

Most of this literature, while stressing the importance of CEO heterogeneity (or the fact that not all CEOs are the same in terms of ability), assumes that leadership talent is readily transferable from one firm-environment to another. For example, the competitive talent assignment models mentioned above presume that CEO talent can be reassigned without cost from one firm to another. Several papers argue that general management skills, which are more transferable across firms than firm-specific skills, have risen in importance over time, and that the greater importance of general management skills has contributed to the observed rapid increase in CEO pay (Murphy and Zábojník (2004), Murphy and Zábojník (2007), Frydman and Saks (2010)).

Other evidence, however, casts doubt on the portability of top management talent. Groysberg, McLean and Nohria (2006) study the performance of firms that recruited 20 former executives from General Electric, widely regarded in the United States as a top training ground for managers, between 1989 and 2001. They note a wide variation in performance, and suggest that this is attributable to the fact that not all of these former GE executives were good "fits" with the firms they went on to manage. The authors argue that while certain types of skills, such as general management skills, transfer well to other firm environments, certain other traits that

\footnotetext{
${ }^{3}$ Chang, Dasgupta and Hilary (2010) find that the stock market reaction to CEO departure announcements is more negative if the prior performance of the firm under the CEO is better and the CEO is more highly paid.
} 
managers either intrinsically possess or acquire in their previous employment might not transfer that readily. ${ }^{4}$

Consistent with the notion that managerial human capital is a portfolio of different skills and assets, an emerging literature suggests that the heterogeneity among CEOs is not simply confined to one attribute, i.e. "talent", and that firms may have different preferences over multiple CEO attributes (Graham, Harvey and Puri (2010), Edmans and Gabaix (2011), Eisfeldt and Kuhnen (2010), Pan (2010), Bandiera, Guiso, Prat, and Sadun (2011), Kaplan, Klebanov and Sorensen (2011)). For example, Graham, Harvey and Puri (2010) find that CEOs who differ in multiple personal characteristics such as overconfidence, optimism, and risk aversion are attracted to different types of firms, and that these characteristics matter for firm performance.

There is, however, to the best of our knowledge, no systematic evidence as to whether and how firms recruit on the basis of fit when both the firms and the managers have multiple characteristics, and what the consequences are if firms recruit managers who do not fit well. The main difficulty is that relevant $\mathrm{CEO}$ characteristics may not be readily observable in large samples. Moreover, since the characteristics of both the firm and the CEO are multi-dimensional, it is not clear which firm and CEO characteristics are most relevant to firm-CEO matching. In this paper, we develop and implement a novel test to demonstrate the importance of matching. We first show, in a simple model of managerial turnover, that when firms try to achieve fit based on their demand for a set of managerial skills arising from a set of firm characteristics, then any such characteristics for the firm the manager leaves (henceforth, old firm) and the firm the manager joins (henceforth, new firm) will covary positively in the cross-section of the turnover sample. Since CEOs may influence corporate decisions and thus firm characteristics - i.e., CEOs may have styles (Bertrand and Schoar, (2003)) - to isolate a matching effect, we investigate the extent to which the pre-turnover characteristics of the new firm can explain the post-turnover

\footnotetext{
${ }^{4}$ For example, John Trani, who in 1997 left GE after spearheading extraordinary growth at GE Plastics, failed as a CEO of Stanley Works because when he joined that company, cost-cutting rather than growth skills were required.
} 
characteristics of the old firm. The choice of timing is key: the manager's influence or style would not affect the new firm's characteristics before his arrival; thus if we find a significant relationship between these two sets of characteristics, it is strong evidence of matching. Our choice of timing also rules out the possibility that contemporaneous shocks that vary over time could explain our results.

We provide comprehensive evidence of fit, or manager-firm matching along multiple dimensions. Further, we show that the market for CEO talent is highly segmented, in the sense that if firms were to randomly pick managers (even from firms within the same industry or size group), they would be much more likely to find a manager with much worse fit than one who fits better. We then demonstrate that fit matters: when firms are not able to appoint managers that are good fits (perhaps because of misplaced importance attached to general management skills, search costs, or market thinness), the stock market reacts less positively, CEO tenure is shorter, and CEO pay is lower. ${ }^{5}$ Finally, we address the issue of how fit and managerial style are related.

We perform several tests, using a sample of top managerial moves between firms. First, in non-parametric tests, we examine whether the characteristics of the old firm and the new firm are "closer" than would be the case under random assignment. To this end, we construct a measure of "distance" between each characteristic of the old firm and the corresponding characteristic of the new firm, as well as the average distance between all the characteristics of the two firms. To avoid scaling issues, each firm characteristic is assigned a decile rank based on which decile in the distribution of that variable the firm characteristic belongs to in a year adjacent to the turnover year. ${ }^{6}$ The distance measure for a particular characteristic for a given

\footnotetext{
${ }^{5}$ In a recent working paper, Pan (2010) shows that, based on structural estimation, diversification and R\&D intensity are relevant to matching, in addition to size. She finds that managers with diversified industry experience generate more matching surplus for diversified firms and that managers with technical degrees are better fits for firms with greater R\&D intensity. Pan also constructs a measure of match quality and shows that it affects market reaction to appointment news announcement, valuation, and duration of tenure.

${ }^{6}$ Specifically, we first sort each firm characteristic for all firms in the Compustat data base in a particular year into deciles, and determine which deciles the corresponding characteristic of the old and the new firm belong to. We
} 
pair of old and new firms is simply the absolute value of the difference in the decile ranks of the characteristic for the two firms. We call this the "decile rank distance" (henceforth, DRD) between the old and the new firm for a particular firm characteristic. In a similar manner, we also determine the "average decile rank distance" (henceforth, ADRD), which is the average decile rank distance for a pair of old and new firms over all the characteristics.

We consider a wide range of firm characteristics similar to Bertrand and Schoar (2003). These variables characterize a firm along multiple dimensions, including operating characteristics (e.g., R\&D expenditure, intangibles, non-discretionary accruals), investment activities (acquisition, capital expenditure, $R \& D$, and growth prospects), financial and organizational structure (e.g., debt ratio, interest coverage and geographical concentration of segments), stock-market related characteristics (e.g., beta, illiquidity, trading volume, book to market, and price-to-earnings ratio).

Strikingly, for all but a few of these characteristics, the sample median value of the decile rank distance is 1 or 2 , suggesting that the characteristics of the old and new firms are quite close. To examine whether random assignment could generate these results, we simulate random assignment. Our simulations reject the null hypothesis that the sample average decile rank distances could be generated by random assignment at significance levels of less than $0.001 \%$. This is true even when the random assignments in our simulations are conditional on the randomly matched firms being from the same size deciles and industries as in the actual sample. $^{7}$

\footnotetext{
consider the old firm characteristic in the year after the turnover and the new firm characteristic the year before the turnover. We explain the rationale for this choice below.

${ }^{7}$ The fact that we find these results even when the randomly matched firms are from the same size deciles as the firms in the actual sample is important for our premise that managers and firms are matched on multiple dimensions other than size and talent, as in the competitive assignment models of Terviö (2008) and Gabaix and Landier (2008). While these models do not directly address how CEOs are likely to be reassigned if, for example, shocks affect firm growth potential and CEOs decide to quit their firms (see, however, Eisfeldt and Kuhnen (2010), discussed further below), the theory is consistent with the observation that the characteristics of the old and new firms are close relative to random assignment. We discuss this further below.
} 
In our second set of tests, we regress an old firm's characteristic after the turnover on the corresponding new firm characteristic prior to the turnover. We find that for the vast majority of the firm characteristics, the pre-turnover five-year average value for the new firm has a significant positive effect on the corresponding post-turnover five-year average value for the old firm. Importantly, these results cannot be explained by a preference that firms might have for recruiting managers from a certain size or industry subgroup.

Overall, our evidence suggests that when firms maximize firm value by searching for the best fit, they end up picking managers from "peers", or firms with similar characteristics, because these firms tend to have similar demand for managerial attributes. A natural question that arises is the following: how likely is it that the fit would worsen if a firm that hires a manager were to randomly pick another firm and hire the manager of that firm instead. This question speaks to how segmented the managerial talent market is. Our estimates suggest that the market is highly segmented: if a sample new firm is matched randomly with another firm from the entire Compustat population, there is an $89.5 \%$ chance that the average decile distance will be larger than that with the actual old firm -- i.e., the fit would be worse. Note that if fit did not matter, there should be no reason to expect that the actual old firm would be different from a firm picked at random in terms of its characteristics, and there would thus only be a $50 \%$ chance that the fit will be worse. A preference for recruiting managers from similar size firms (or industry) does not explain the segmentation: even when we pick the randomly matched firm from the same size decile (same industry) as the actual old firm, the probability that fit would worsen is $81.5 \%(82.5 \%)$.

Next, we examine whether fit matters for firm value. In the process of reassignment of managers to firms due to shocks, retirements, etc., not all firms achieve the same degree of fit (or match) with their new manager. We formulate a measure of match quality of a manager with the new firm based on the set of variables that we identify as match-relevant. Consistent with the notion that fit matters, we find that a lower degree of fit is: (i) negatively related to the 
appointment news cumulative abnormal returns at the new firm, (ii) negatively related to the tenure of the manager at the new firm (consistent with the notion that managers who are better fits to begin with are more likely to survive shocks), and (iii) negatively related to total compensation of the manager at the new firm.

In an important paper, Bertrand and Schoar (2003) demonstrate that managers have unique management styles. In particular, they show that "manager-specific fixed effects" affect characteristics of firms that employ the same manager. Since all our tests demonstrate that characteristics of the new firm before the turnover are related to those of the old firm after the turnover, our results cannot be simply explained by managerial style. However, our results by no means preclude style: if style is related to managerial attributes, our results are perfectly consistent with style. It is unlikely, though, that managerial style would influence corporate policies if firms always succeeded in hiring managers whose style is what they need, consistent with firm-manager fit. Thus, to identify style effects, one needs to examine managerial moves associated with imperfect fit. We find that, for several firm characteristics, when the preturnover distance between a new and old firm characteristic is larger, a characteristic changes more in the direction of the old firm's pre-turnover characteristic after the turnover, consistent with a managerial style effect.

Our paper contributes to a growing literature that finds evidence consistent with the notion that managers and firms are matched on multiple dimensions. Our approach has several advantages. First, it does not rely on explicit measures of managerial talent, expertise, or attributes, and thus can be readily implemented using information for public firms that disclose standard accounting and financial information and hire new top managers from other firms which disclose similar information. Second, it allows us to formulate an empirical measure of match quality that does not require a direct estimation of a match production function, nor does it rely on the match production function being correctly specified. This is an important advantage because there is not much theoretical guidance as to which firm characteristics and 
managerial attributes complement each other, and it is not clear to what extent empirical researchers can fully capture these characteristics.

The rest of the paper proceeds as follows. The next section sets up a basic model of managerial turnover, formalizes the notion of "fit", and provides the motivation for our empirical tests. Section 2 describes our empirical design and our sample. Our empirical results on manager-firm fit are in Section 3, and Section 4 details how match quality affects firm value, managerial pay and tenure. Section 5 discusses the relationship of our work to the "managerial style" literature. Section 6 concludes the paper.

\section{A Model of Managerial Turnover and Fit}

In this section, we present a simple model of managerial turnover that incorporates a notion of "fit" and assumes that firm-manager fit impacts firm value. The main purpose of the model is to generate the following implication that we test in the empirical section of the paper: if a manager moves from an old firm to a new firm, and fit between an observed firm characteristic X (e.g., R\&D intensity) and an unobserved managerial attribute (e.g., capacity to innovate) is relevant for a good match between a firm and the manager, then a regression of the old firm's $\mathrm{X}$ on that of the new firm will generate a positive coefficient on the latter. As we discuss later, the design of this regression will be such that we can rule out the possibility that X in both firms is influenced by the same manager, that is, it reflects managerial style. The reader not interested in the details of our model can move on to Section 3 with any loss of continuity.

While shocks to a firm's environment can undoubtedly change the nature of the firm and lead to managerial turnover (Eisfeldt and Kuhnen (2010)), not all managerial transition events from one firm to another are the outcome of such shocks. In particular, in our model, we want to focus on the notion that events such as CEO retirements or sudden deaths can lead to reassignment of CEOs to other firms and cause turnover in the managerial labor market. 
Consider an economy with $\mathrm{N}$ firms and two dates, $\mathrm{t}=0$ and $\mathrm{t}=1$. The value of firm $i$ at each point of time is given by

$$
G^{i}\left(a_{1}^{i}, \cdots, a_{m}^{i} ; b_{1}^{k}, \cdots, b_{m}^{k}, e\right)=g^{i}\left(a_{1}^{i}, \cdots, a_{m}^{i}\right) f\left(a_{1}^{i}, \cdots, a_{m}^{i} ; b_{1}^{k}, \cdots, b_{m}^{k}\right)
$$

where $\bar{a}^{i}=\left(a_{1}^{i}, \cdots, a_{m}^{i}\right)$ is a vector of $\mathrm{m}$ firm characteristics and $\bar{b}^{k}=\left(b_{1}^{k}, \cdots, b_{m}^{k}\right)$ is a vector of m manager characteristics, $i$ indexes a firm and $k$ indexes a manager. The assumption that the number of firm and manager characteristics is the same is without any loss of generality. The variable e denotes managerial effort. Since incentive issues are not the focus of our paper, we will assume that $\mathrm{e}$ is at its optimal value for firm $\mathrm{i}$, and is subsumed in the function $\mathrm{g}^{\mathrm{i}}($.$) .$

We call the function $\mathrm{f}(. ;$. .) firm $i$ 's fit with manager $k$. For expositional simplicity, we assume that $\mathrm{f}(. ;$.$) has the following form:$

$$
f(\bar{a}, \bar{b})=\frac{1}{m} \sum_{s=1}^{m}\left(a_{s}^{i} b_{s}-\left(b_{s}\right)^{2}\right)
$$

Then the "best-fit" manager for firm i has managerial characteristics that maximize expression (1). These characteristics of the best-fit manager are given by

$$
b_{s}^{i}=\frac{a_{s}^{i}}{2}, \quad s=1, \cdots, m .
$$

The particular functional form assumed for the fit function is for expositional convenience only, and none of our conclusions depend on this particular functional form (including the equal weighting of attributes). ${ }^{8}$

The critical element of fit is the idea that for each firm characteristic, there is an interior optimal level of a particular managerial attribute, as in equation (2). For example, a firm might need a moderate amount of cost-cutting; a manager who is not known for cost-cutting would not be a good choice, nor would a very aggressive cost-cutter. As another example, consider a firm that has $40 \%$ of its assets in one line of business (industry A), and 20\% in each of 3 other lines. A manager who has managed a firm that was completely focused in industry $\mathrm{A}$ is not an ideal

\footnotetext{
${ }^{8}$ Other function forms for the fit function give similar results, for example, if we assume each term in the right hand side of Equation (2) to be of the form $-\left(a_{s}-b_{s}\right)^{2}$.
} 
choice; nor is a manager who has managed a firm with many lines of business, with industry A representing only $10 \%$ of that business.

Substituting Equation (3) into Equation (2), we get the value of firm $i$ when it has its "best-fit" manager:

$$
G^{i}\left(\bar{a}^{i} ; \bar{b}^{*}\left(\bar{a}^{*}\right), e^{*}\right)=\frac{1}{4 m} g^{i}\left(\bar{a}^{i}\right) \sum_{s=1}^{m}\left(a_{s}^{i}\right)^{2}
$$

We assume that at $\mathrm{t}=0$, each firm has its best-fit manager, so firm value is as in Equation (4). Each firm also has a potential "insider" who can run the firm. This insider, however, is not as good a fit as the current "CEO manager". Specifically, we assume that the insider has the exact same managerial attributes as the CEO except one: he/she does not have the "experience" of leading the firm. This causes the firm's value to be lower if it is run by the insider by a factor $\alpha<1$ :

$$
G_{I N}^{i}\left(\bar{a}^{i} ; \bar{b}^{*}\left(\bar{a}^{*}\right), e^{*}\right)=\frac{1}{4 m} g^{i}\left(\bar{a}^{i}\right) \alpha \sum_{s=1}^{m}\left(a_{s}^{i}\right)^{2}
$$

where we have assumed that the insider can be replaced in his current function at no cost. ${ }^{9}$

The value loss for the firm being run by an insider is given by

$$
\Delta G_{I N}^{i}=\frac{1}{4 m} g^{i}\left(\bar{a}^{i}\right)\left((1-\alpha) \sum_{s=1}^{m}\left(a_{s}^{i}\right)^{2}\right)
$$

Suppose instead that firm $i$ is run by one of the managers currently managing one of the other $\mathrm{N}$ firms, e.g., the manager of firm $j \neq i$. Using the same superscript to denote a "best-fit" pair of manager and firm, we can write the value loss to firm $i$ as

\footnotetext{
${ }^{9}$ This assumption is not crucial to our conclusions.
} 


$$
\begin{aligned}
& G^{i}\left(\bar{a}^{i}, \bar{b}^{i}\right)-G^{i}\left(\bar{a}^{i}, \bar{b}^{j}\right) \\
& =\Delta G_{j}^{i} \\
& =\frac{1}{m} g^{i}\left(\bar{a}^{i}\right)\left(\sum_{s=1}^{m}\left\{\left(a_{s}^{i} b_{s}^{i}-\left(b_{s}^{i}\right)^{2}\right)-\left(a_{s}^{i} b_{s}^{j}-\left(b_{s}^{j}\right)^{2}\right)\right\}\right) \\
& =\frac{1}{m} g^{i}\left(\bar{a}^{i}\right)\left(\sum_{s=1}^{m}\left\{\left(a_{s}^{i}-\left(b_{s}^{i}+b_{s}^{j}\right)\right) \cdot\left(b_{s}^{i}-b_{s}^{j}\right)\right\}\right) \\
& =\frac{1}{4 m} g^{i}\left(\bar{a}^{i}\right)\left(\sum_{s=1}^{m}\left(a_{s}^{i}-a_{s}^{j}\right)^{2}\right)
\end{aligned}
$$

where the last step follows from Equation (3).

Consider now time $\mathrm{t}=1$. At this time, assume that firm $i$ loses its "best-fit" CEO due to some exogenous reason (retirement, sudden death etc.). Given our assumption that the insider or second-in-command in each firm lacks experience of the CEO job and hence there is a loss of productive efficiency if he/she takes over, it follows that the successor must be either the insider, or one of the other N-1 CEOs. ${ }^{10}$ The following is a sufficient condition that there is an outsider succession in firm $i$ : there exists some $j$ such that

$$
g^{i}\left(\bar{a}^{i}\right)\left((1-\alpha) \sum_{s=1}^{m}\left(a_{s}^{i}\right)^{2}-\sum_{s=1}^{m}\left(a_{s}^{i}-a_{s}^{j}\right)^{2}\right) \geq g^{i}\left(\bar{a}^{j}\right)\left((1-\alpha) \sum_{s=1}^{m}\left(a_{s}^{j}\right)^{2}\right)
$$

Condition (8) requires that the loss of value to firm $j$ in giving up a CEO and being managed by an insider (proportional to the expression on the right-hand-side) is less than the gain to firm $i$ hiring that same manager compared to being run by its insider. ${ }^{11}$

Notice that this condition cannot hold if firm $j$ is a higher value firm with its best-fit CEO than firm $i$, or roughly, it requires that the firm relinquishing the CEO be of smaller size.

\footnotetext{
${ }^{10}$ This is because the firm's insider always dominates any other insider since they are both associated with the same loss of productive efficiency, but the fit is better for the firm's insider.

${ }^{11}$ Note that condition (8) is sufficient, but not necessary, for a CEO move to occur. The loss to firm $j$ would be lower than indicated by the expression of the right-hand-side of (8) if $j$ can recruit a manager from outside who creates more value than the insider (see below), and so on. However, clearly, given that there is one less CEO, some firm must be run by its insider, and condition (8) must apply for at least one pair of firms.
} 
Such a phenomenon is strongly supported by our data on actual managerial moves, and is further discussed in section 2.2 below. $^{12}$

So far, the model only accommodates CEO-to-CEO moves. A large number of moves in the data are moves from non-CEO managerial positions to $\mathrm{CEO}$ positions in other firms. Such moves can be easily accommodated by assuming that between time $\mathrm{t}=0$ and $\mathrm{t}=1$, a fraction of insiders "learn" how to manage the firm as a CEO without any efficiency loss (so that $\alpha=1$ for such managers). Since we have normalized the loss to the firm from losing an insider to 0 , if firm $j$ is such a firm, condition (8) only requires that the left hand side be non-negative. Such moves do not have to be from smaller to larger firms, as implied by condition (8). We therefore expect a much higher proportion of such moves (i.e., non-CEOs to CEO positions) to be associated with moves from larger to smaller firms (again strongly supported by data). ${ }^{13}$

If an outside succession is observed, it must be the case that

$$
\Delta G_{I N}^{i}-\Delta G_{j}^{i} \geq 0
$$

which requires

$$
\sum_{s=1}^{m}\left(\left((1-\alpha)\left(a_{s}^{i}\right)^{2}-\left(a_{s}^{i}-a_{s}^{j}\right)^{2}\right)\right) \geq 0
$$

We now come to our first result. We will assume for simplicity that firm characteristics $a_{s}^{i}, s=1, \ldots, m$, are independently distributed random variables, and the $a_{s}^{i}$ are identically and independently distributed for $\mathrm{i}=1, . ., \mathrm{N}$.

\footnotetext{
${ }^{12}$ This follows because if (8) holds, we must also have $g^{i}\left(\bar{a}^{i}\right)\left((1-\alpha) \sum_{s=1}^{m}\left(a_{s}^{i}\right)^{2}\right) \geq g^{i}\left(\bar{a}^{j}\right)\left((1-\alpha) \sum_{s=1}^{m}\left(a_{s}^{j}\right)^{2}\right)$.
}

Canceling the common (1- $\alpha)$ from both sides and dividing by $(1 / 4 \mathrm{~m})$, we get the firm value (size) in each side.

${ }^{13}$ CEO-to-non-CEO moves occur only in $7 \%$ of our sample and often lead to the new manager eventually taking over as CEO. Therefore, we do not discuss these cases separately here. In our sample, CEO-to-CEO moves occur in $44 \%$ of the cases, and Non-CEO-to-CEO moves occur in $49 \%$ of the cases. The median (mean) ratio of the size (i.e., market value) of the new firm to that of the old firm for the CEO-to-CEO moves sample is 1.79 (5.46); that for the Non-CEO-to-CEO sample is $0.2(0.56)$, and that for the CEO-to-Non-CEO sample is 2.71 (7.86). Book value ratios are similar. 
Proposition 1. Conditional on outside succession occurring for firm $i, E\left(a_{s}^{j} \mid a_{s}^{i}\right)$ is increasing in $a_{s}^{i}$ for $s=1, \ldots, m$.

Proof. We provide a proof for the case of $\mathrm{m}=1$. The case of $\mathrm{m}>1$ is given in Appendix 1 .

For $\mathrm{m}=1$, Equation (10) reduces to

$$
(1-\alpha)\left(a_{1}^{i}\right)^{2}-\left(a_{1}^{i}-a_{1}^{j}\right)^{2}>0 .
$$

It is easy to check that the two roots of $a_{1}^{j}$ for which (11) holds with equality are given by $a_{1}^{j^{*}}=(2-\theta) a_{1}^{i}$ and $a_{1}^{j^{* *}}=\theta a_{1}^{i}$, where $\theta=\sqrt{1-\alpha}+1$. Equation (11) holds for intermediate values of $a_{1}^{j}$. Note that $a_{1}^{j^{*}}<a_{1}^{j * *}$ and that both roots are increasing in $a_{1}^{i}$.

Let $F($.$) denote the cumulative distribution function of a_{1}^{j}$. The conditional cumulative distribution function (conditional CDF) of $a_{1}^{j}$ given that (11) holds is given by $P\left(a_{1}^{j} \mid a_{1}^{i}\right)=\frac{F\left(a_{1}^{j}\right)-F\left(a_{1}^{j^{*}}\right)}{F\left(a_{1}^{j^{* *}}\right)-F\left(a_{1}^{j^{*}}\right)}$. It is easily checked that $\frac{\partial P\left(a_{1}^{j} \mid a_{1}^{i}\right)}{\partial a_{1}^{i}}<0$. Thus, a higher $a_{1}^{i}$ improves the distribution of $a_{1}^{j}$ in the sense of first-order stochastic dominance, and the result follows. (QED)

Discussion. To see the intuition for the result, first consider what would have happened had the first term in (11) been constant. In that case, $a_{1}^{j}$ would have to be in an interval of fixed length defined by the bounds $a_{1}^{i} \pm k$, and thus would have to co-vary with $a_{1}^{i}$. The reason is that the fit would have to be close enough for the outside succession to improve upon the inside succession. Essentially the same intuition applies when the first term in (11) also increases in $a_{1}^{i}$. However, since the loss from an insider succession now increases with $a_{1}^{i}$, the fit also worsens somewhat as $a_{1}^{i}$ increases.

Proposition 1 provides the basis for the empirical tests discussed in the next section. 
From Equation (7), we see that the metric $\frac{1}{4 m}\left(\sum_{s=1}^{m}\left(a_{s}^{i}-a_{s}^{j}\right)^{2}\right)$ serves as a natural measure of how good the fit is between firm $i$ and the outside hire. Our empirical counterpart of fit (or mis-fit) is closely related and is based on the distance between the characteristics of the old and the new firm. However, an important caveat in utilizing the fit measure is the following. The model outlined here has assumed that at $\mathrm{t}=0$, each firm has its "best-fit" manager, which is a modeling convenience but unlikely to hold in the data. In particular, some managers may be poor fits with their current firms but may stay on either because they have become entrenched or because managerial characteristics are imperfectly observed when a CEO is appointed but are observed more precisely over time. In the next section, we discuss how we "control" for fit at the old firm in examining how our measure of fit affects the market reaction to outside appointment news.

We next develop some implications for cross-sectional variations in the fit measure, suitably modified to reflect the fit at the old firm.

(i) Appointment Announcement Effect. Clearly, the worse the fit, the lower the value of the firm the CEO joins; consequently, we expect a lower "announcement effect" on the new firm's stock price if the fit is worse. Note that the "announcement effect" presupposes that the market cannot predict perfectly who the replacement will be prior to the announcement. Our model suggests one scenario where this will hold - e.g., if the insider efficiency parameter $\alpha$ is firm-specific and not observed by the market.

(ii) Tenure at New Firm. Both firms' characteristics can change over time. It is clear from (11) that the tighter the initial fit, the more likely it is that condition (11) will survive shocks to $a_{1}^{i}$ that are uncorrelated with the levels of the two variables. Hence, one would expect that CEOs that are worse fits would have shorter tenures. 
(iii) Compensation. We lack a formal theory of compensation determination for the assignment framework illustrated above. However, to the extent that better fit improves the match surplus, one can conjecture that the CEO's pay will increase with fit.

\section{Empirical Design and Managerial Turnover Sample}

In this section, we discuss how we design the empirical tests of our hypotheses and construct the sample.

\subsection{Hypotheses and Estimation Strategy}

Since CEO characteristics or skills are largely unobserved, we identify CEO-firm matching in a framework that takes advantage of the fact that the same CEO may work for two different firms over adjacent periods of time. As Proposition 1 shows, if CEOs and firms are matched based on the latter's demand for certain types of managerial skills, then two firms that employ the same CEO during adjacent periods should have related characteristics. The main concern is, however, that CEOs may influence corporate decisions and thus firm characteristics - i.e., CEOs have styles (Bertrand and Schoar, 2003). To rule out the possibility that CEO style influences our results, we do not examine the association between characteristics of the old firm prior to turnover and those of the new firm after the turnover, although to do so might seem natural. Moreover, we choose not to examine the association of the characteristics over overlapping periods since we are concerned about correlation due to contemporaneous effects. Thus, we examine the relationship between pre-turnover average values of characteristics of the new firm and post-turnover average values of the old firm. ${ }^{14}$

We construct a sample of pairs of firms in which the manager of one firm (the old firm) leaves to become the manager of another firm (the new firm) - a detailed description of the

\footnotetext{
${ }^{14}$ Proposition 1 (based on which our empirical tests are designed) also assumes that firm characteristics are unaffected by managerial attributes. Some of our proxies for firm characteristics, such as operating characteristics, may well depend on who manages the firm. As we argue in section 5 when we consider the relationship between fit and managerial style, such phenomena are more likely when the initial fit is not very good, so the if the characteristics change, they become more informative about managerial attributes.
} 
sample construction process is in the next subsection. We examine a wide range of firm characteristics similar to Bertrand and Schoar (2003), including operating characteristics, investment activities, financial and organizational structure, and stock-market related characteristics. The full list of variables and the corresponding descriptive statistics are in Panel B of Table 1.

For each of the variables of interest, we estimate the following models:

$$
X_{\text {post }}^{\text {old }}=\alpha_{0}+\alpha_{1} X_{\text {pre }}^{\text {new }}+e
$$

and

$$
X_{\text {post }}^{\text {old }}=\beta_{0}+\beta_{1} X_{\text {pre }}^{\text {new }}+\beta_{2} X_{\text {pre }}^{\text {new }} \cdot I_{I N D}+\beta_{3} X_{\text {pre }}^{\text {new }} \cdot I_{S I Z E}+e
$$

where superscripts new and old indicate the pair of new and old firms that employ the same manager, the subscripts pre and post indicate the years prior and subsequent to the year of managerial turnover. $X_{\text {post }}^{\text {old }}$ is the average of the old firm's $\mathrm{X}$ over the 5 fiscal years after the turnover year, and $X_{p r e}^{\text {new }}$ is the average of the new firm's X over the 5 fiscal years prior to the turnover. The specifications in Equations (12) and (13) that treat the old firm characteristics as the dependent variables and the new firm characteristics as the independent variables directly follow from a linearized version of the relationship between new and old firm characteristics in Proposition 1.

From Proposition 1, evidence of fit corresponds to $\alpha_{1}>0$ in Equation (12). We also estimate an augmented model (Equation (13)) in which we introduce two interaction terms. I IND is an indicator variable that takes a value of 1 if the new and old firms are from the same industry, and zero otherwise. $\mathrm{I}_{\text {SIZE }}$ is an indicator variable that takes the value of 1 if the new and old firms are from the same or adjacent size deciles, and zero otherwise. A significant positive 
coefficient $\left(\beta_{1}\right)$ for $X_{\text {pre }}^{\text {new }}$ implies that the positive association is not limited to moves within an industry, or the same or adjacent size deciles.

This part of the analysis can be summarized in the following hypothesis:

\section{Hypothesis 1}

Suppose firm-manager fit depends on a vector $\boldsymbol{X}$ of firm characteristics and a vector $\boldsymbol{Y}$ of managerial attributes. If $X$ is an element of $\boldsymbol{X}$, then the old firm's characteristic $X$ after the manager leaves the old firm will be positively related to the new firm's $X$ before the same manager joins the new firm.

After we identify the set of variables for the old and the new firm that are related in the sense of Hypothesis 1 and are revealed to be relevant for firm-manager matching, we formulate a measure of the quality of the match. Our measure is an inverse measure of match quality, or a measure of "mismatch" between the new firm and the manager, and is based on the distance between old and new firms' match-relevant characteristic. We discuss this measure in more detail in Section 4. One caveat, however, is that the distance between the old and the new firm is an appropriate measure of mismatch of the manager with the new firm only under the assumption that the manager was a good fit with the old firm in the first place. ${ }^{15}$ We measure the manager's fit with the old firm based on that firm's performance in the three years prior to the manager's departure from the firm. Specifically, we consider the fit with the old firm to be good if the buy-and-hold return over the last three years exceeds the industry median. Accordingly, our mismatch variable has a clean interpretation only for the subsample of managerial moves for which the past three year buy-and-hold return at the old firm exceeds the industry median. For comparison, however, we also report results for the subsample for which the buy-and-hold return is below the industry median.

\footnotetext{
${ }^{15}$ For example, a CEO could be a poor fit for the old firm but a good fit with the new firm. In this case, the distance between the new and the old firm characteristics will also be large.
} 
Building on the discussion in Section 1, we now formulate three hypotheses pertaining to match quality. First, when the match quality between the new firm and the manager is poorer, the stock market should react more negatively when the company announces the news that the manager is hired. Hence, we have the following hypothesis:

\section{Hypothesis 2}

Poorer match quality between the manager and the new firm is associated with a smaller stock market wealth effect of the appointment news of the manager at the new firm. ${ }^{16}$

Second, all else being equal, when the manager is a poorer fit with the new firm, he is expected to remain at the new firm for a shorter period.

\section{Hypothesis 3}

Poorer match quality between the manager and the new firm is associated with shorter tenure of the manager in the new firm.

Finally, we expect that a poorer fit will result in smaller compensation for the manager at the new firm.

\section{Hypothesis 4}

Poorer match quality between the manager and the firm is associated with lower compensation for the manager at the new firm.

We estimate the impact of match quality in the following regression framework.

$$
Y_{t}^{\text {new }}=a_{0}+a_{1} \text { Mismatch }+a_{2} X_{t-1}+e_{t}
$$

where $\boldsymbol{Y}_{t}^{\text {new }}$ is the outcome variable, including announcement CAR, tenure duration, and pay. These outcome variables will be defined in detail in Section 4. The mismatch variable is a reliable inverse measure of fit between the manager and the new firm if the manager is a good fit

\footnotetext{
${ }^{16}$ It is worth emphasizing that Hypothesis 2 does not presuppose that the stock market knows when a manager is poorly matched, but the firm does not. If the pool of managers with attributes that the firm desires is limited, there will be variation in the quality of fit. The market will have "average" expectations about the quality of the fit, and will react negatively when the actual fit is below average. The model outlined in the previous section suggests that if the quality of the pool of potential successors within the firm is poorer, the firm may settle for a poorer fit if it recruits from outside. The market may be initially uninformed about the quality of the inside pool, and thus will be "surprised" by the actual fit with the outsider.
} 
with the old firm. As discussed above, empirically, when the old firm's three-year buy-and-hold stock return prior to the managerial turnover is above the industry median, we consider the fit between the manager and the old firm to be good.

\subsection{Sample Construction and Summary Statistics}

We first construct a sample of CEO turnover events. We start from the ExecuComp database, which covers S\&P1500 firms from the year 1992. ExecuComp allows us to track the names of 5611 CEOs in 1500 publicly listed U.S. firms during the period 1992-2007. If the name of the $\mathrm{CEO}$ of a firm in year $\mathrm{t}$ is different from that of the CEO in year $\mathrm{t}-1$, we define this as a turnover event. We obtain 2687 turnover events. Each turnover event involves a departing CEO and a new CEO.

Our empirical design requires that the CEO leaving an ExecuComp firm join another listed firm, so that accounting and stock market data are available. For each departing CEO from the ExecuComp sample of the turnover events, we conduct a news search using Lexis-Nexis or Factiva and study the relevant proxy statements to identify the date of the turnover announcement and the CEO's employment history, his/her period of tenure in each employment, as well as the company that he/she joins, the date he/she joins the company, and his/her position at the new company. This gives us 198 cases.

Similarly, for each new CEO that joins an ExecuComp turnover firm, we conduct a news search using Factiva or Lexis-Nexis and study the relevant proxy statements to identify those cases in which the CEO was in a managerial position of another listed company prior to the turnover. This yields an additional 188 cases. ${ }^{17}$ Overall, in our turnover sample, we have 171 CEO-to-CEO moves, 27 CEO-to-non-CEO moves, and 188 non-CEO-to-CEO moves. ${ }^{18}$ From

\footnotetext{
${ }^{17}$ Thus, the manager in our turnover sample holds a CEO position in either the old or the new firm.

${ }^{18}$ In a few cases, the manager first takes up a senior managerial position and then moves to the CEO position
} 
these turnover cases, we construct a sample of firm pairs that employ the same top managers during adjacent time periods.

For all our regressions except those where our key dependent variable is fit, we require that the tenure of the manager at both firms is at least two years, excluding the year the manager leaves (joins) the old (new) firm. The median duration between jobs for our sample managers is 40 days, and the mean is 279 days. This is consistent with the notion that our sample managers move because of opportunities in the labor market rather than poor performance at the firms they manage. $^{19}$

Groysberg et al. (2006), examining the performance of firms that employed senior management from GE, argue that the divisional experience of many of these executives in GE determined whether they turned out to be good fits for the companies that hired them. If the nonCEO executives in our sample were divisional managers in lines of businesses that are not in the firm's main line of business, it is possible that the overall firm characteristics are not well matched to the managerial attributes. If this is the case, our approach of identifying fit based on characteristics of the old and the new firm will be noisy. However, this possibility only biases against finding associations between old and new firm characteristics, i.e., identifying fit.

Few companies in our sample, however, have as deep a pool of management talent as GE, widely regarded, along with AT\&T, IBM and McKinsey, as "talent generators" in the CEO market (Groysberg et al. (2006)). To purge our fit measures of noise as much as possible, we examined whether the non-CEO executives: (a) hold a "company level" position such as COO of the company, President of the company, or CFO of the company; (b) are among the five highest paid executives in the company in the year before the turnover (suggesting "company level" importance of the function, or of the unit), and (c) are from "pure play" firms with only

\footnotetext{
${ }^{19}$ Chang, Dasgupta and Hillary (2010) study a sample of CEO turnovers. The cumulative abnormal returns around the departure announcement for the subsample (41\% of the overall sample) in which the CEO finds another managerial appointment is significantly negative, suggesting that these turnovers involve CEOs who are valuable to the firms. In contrast, the CAR for the complementary subsample where the CEOs have no new managerial appointments in the next 3 years is zero. The authors also find that "bad news" announcements for the latter subsample around the departure announcement are more likely than for the former.
} 
one distinct 2-digit SIC code describing their lines of business. For non-CEO executives that did not meet any of the above conditions, we searched the news around their appointment to determine whether, in their previous employment, they were involved in activities related to the company's main line of business. This procedure left us with 12 executives who could not be linked to the previous company's main line of business or to company level functions with certainty. Dropping these 12 executives has no effect on any of the results reported in the paper.

Panel A in Table 1 presents information on the different types of managerial transitions from the old firm to the new firm. $44 \%$ of the moves are CEO-to-CEO moves, $49 \%$ are nonCEO-to-CEO moves, and the remaining 7\% are CEO-to-Non-CEO moves. Consistent with the model outlined in Section 1, CEOs typically move to much larger firms as CEOs; non-CEO top managers typically move to smaller firms as CEOs.

Our accounting and financial variables come from Compustat; the stock market related variables are from CRSP. Data on executive pay are from ExecuComp. Panel B in Table 1 presents the firm-specific variables we examine, and means and medians of those variables for the sample of new and old firms for the period 1987-2009. ${ }^{20}$ The construction of these variables is detailed in Appendix 2. Following Bertrand and Schoar (2003), we also examine the means and medians of the corresponding variables for the largest (in terms of market value) 1500 firms in Compustat. This is a relevant benchmark because $85 \%$ of the firms in the turnover sample are in Execucomp, which covers the S\&P1500 firms.

Panel B in Table 1 shows that, except for firm size, the means and medians of most firm characteristics for the old and the new firms, though statistically different in about one half of the cases, are typically very similar in terms of magnitude, consistent with matching. Moreover, given the size difference, it is unlikely that similarities in size are driving the similarity of the firm characteristics. Interestingly, the new and old firm characteristics in our turnover sample

\footnotetext{
${ }^{20}$ We begin in 1987 because the earliest appointment year is 1992 and in estimating Equation (12), we go back 5 years from the year of turnover to construct the five year average values of the characteristics.
} 
are more often statistically different, and in almost all cases economically significantly different, from those of the Compustat sample of the largest 1500 firms.

\section{Empirical Results: Manager-Firm Matching}

In this section, we provide a variety of evidence on the extent to which we have sorting of firm characteristics among firms that hire a manager (holding a CEO position in at least one of the firms) at adjacent intervals of time. To claim that such sorting is evidence of multidimensional manager-firm matching, however, we need to show that sorting on firm size alone cannot produce the extent of sorting among firm characteristics we observe in the data. This is because, even though the competitive assignment models of Terviö (2008) and Gabaix and Landier (2008) do not directly address how CEOs are likely to be reassigned (if, for example, shocks affect firm growth potential and CEOs decide to quit their firms), the theory is consistent with the observation that the characteristics of the old and new firms are "close" relative to random assignment. ${ }^{21}$ According to these models, the most talented managers are initially assigned to the largest firms. Thus, when a large firm loses a manager, it is likely to recruit another (highly talented) manager leaving another large firm. Since size may be a proxy for many firm characteristics, data could reveal that the "old firm" and "new firm" characteristics are closer than they would be under random matching. In the results discussed below, by controlling for size, we ensure that our evidence of matching is not driven by size-talent assignment. Similarly, firms may often have a preference for managers from the same industry for reasons of familiarity, even though this fact itself can be considered evidence of segmentation that extends beyond firm size. Therefore, we also control for industry.

\subsection{Non-parametric Results}

\footnotetext{
${ }^{21}$ To the best of our knowledge, Eisfeldt and Kuhnen (2010) is the only paper that addresses turnover in a competitive assignment model framework. In the model, managers have multidimensional skills and firms have multidimensional skill weights. However, firms are of the same size. Turnover occurs because a shock to one type of firm changes the weight they put on the particular type of general skills that some managers have.
} 
Before discussing the empirical tests motivated by Hypothesis 1, we present results from some non-parametric tests. From equation (10), it is immediate that for a given level of an old firm characteristic, the "distance" between the level of that characteristic and that of the corresponding new firm characteristic will be smaller than if the latter were from a random firm in the population. The tests reported below verify this implication. We find strong support, and show that the results are not driven by a preference for firms to recruit managers from other firms of a particular size or from a particular industry.

In Tables 2 and 3, we present evidence that the sample average characteristics of the old and new firms are "closer" than what could be expected based on random assignment, even when the random assignment is conditional on the same size decile and industry groups as in the actual sample. To this end, we construct a measure of the "distance" between each firm characteristic for each old and new firm pair, as well as a corresponding measure of the average distance of all characteristics. Specifically, we sort each variable of interest (a full list is in Table 1) for all firms each year in the Compustat data base into deciles. For each new and old firm, we determine to which decile of the distribution the corresponding firm characteristic belongs, and assign a "decile rank" (taking values from 1 to 10). For an old firm characteristic, the relevant year is the one immediately after the turnover, while for a new firm characteristic, the relevant year is the one immediately before the turnover. This choice of time periods is made to avoid the possibility that these characteristics are similar because they are influenced by the same manager.

The "decile rank distance" (henceforth, DRD) is the absolute value of the difference in decile ranks of each characteristic between the new and the old firm, and is an inverse measure of how close a particular pair of old and new firms are to each other in terms of that characteristic. In the same way, for each pair, we also compute an "average decile rank distance" (henceforth, ADRD); this is a simple average of the decile rank distance for all characteristics, and is a measure of how close the new and the old firm are, overall. 
Table 2 reports the sample mean, median, the $25^{\text {th }}$ and the $75^{\text {th }}$ percentile values of the ADRD as well as the DRD for each individual characteristic. The median value of the average distance is 2 , and for most of the individual characteristics, the median distance is either 1 or 2 , suggesting that the new and old firm characteristics generally belong to adjacent deciles. All the mean DRD's are smaller than 3.3 (which is the expected DRD if, given a decile rank for a new firm characteristic, the corresponding old firm characteristic is uniformly distributed over deciles 1 through 10).

In Table 3, we systematically benchmark these numbers against what could be expected under random assignment. For each new firm, we randomly pick another firm (a "pseudo old firm") from Compustat in the year after the turnover, and pretend that this is the firm that is matched with the new firm. We do so for each new firm in the sample to generate a new sample of new and randomly matched pseudo old firms. We then compute the sample mean and median decile rank distance for each firm characteristic, as well as the ADRD over all characteristics. We repeat this exercise 1000 times to determine the percentage of times the means and medians in the simulation samples are smaller than those in the actual sample.

Remarkably, as reported in column (1) of Table 3, Panel A, the sample median value of the ADRD for all 1000 random samples exceeds or equal that for the actual sample. Moreover, this is also the case for the sample median DRDs for all but 2 of the individual characteristics. The two characteristics in Panel A for which the exception occurs are excess return and leverage, but even here, medians of the random samples exceed or equal those for the actual sample more than $95 \%$ of the times. The results for the sample means in Panel B are similar.

As discussed above, although the size-talent assignment models of Terviö (2008) and Gabaix and Landier (2008) do not address CEO turnover, it is conceivable that such models would predict that firms that lose CEOs will recruit CEOs from other firms of similar size. Therefore, to demonstrate that CEO-firm assignment is on the basis of characteristics other than firm size and $\mathrm{CEO}$, we repeat the exercise by making the random assignment conditional on the 
pseudo old firm being drawn from the same size decile as the actual old firm. Moreover, even though as much as $33 \%$ of the managers in our turnover sample are recruited from the same industry, (suggesting a preference for what Groysberg et al. (2006) call "industry human capital”, an important consideration for 'fit'), it could be argued that this merely reflects familiarity with managers in the same industry that mitigates search cost. While this does not invalidate the claim that the $\mathrm{CEO}$ market is segmented, it is important to know to what extent common industry characteristics explain "fit." To this end, in another exercise, we make the random assignment conditional on the pseudo old firms being drawn from the same industry as the actual old firm. Results for these conditional assignments are reported in columns (2)-(3) of Table 3. Remarkably, even after conditioning on both size and industry, the sample median ADRDs for the random samples exceed or equal that for the actual sample in all cases. This is also the case for the sample median DRDs for most other individual characteristics.

These results provide compelling evidence of non-random assignment which goes beyond a preference for managers from firms in particular industries or size categories. The top managerial market appears segmented. If managerial talent were readily transferable from one firm-environment to another, then it is unlikely that we would observe that firms losing managers generally recruit new managers from firms that are especially close to them in so many characteristics. In Section 3.3, we present some evidence on the extent of segmentation of the top managerial talent market.

\subsection{Which Firm Characteristics are Relevant for Manager-Firm Match?}

In this section, we present our main tests on manager-firm matching. That is, we use a regression framework to evaluate the strength of the cross-sectional covariance between new and old firm characteristics implied by manager-firm matching (Proposition 1). An important advantage of these tests is that they allows us to identify which firm characteristics are relevant for matching when firm characteristics are multi-dimensional. 
We first report which of the old firm post-turnover characteristics can be explained by the new firm pre-turnover characteristics. Table 4 reports the estimation results of Equations (12) and (13). Regressions results are reported only for those variables for which either $\alpha_{1}$ or $\beta_{1}$ are significantly different from zero. Recall that $\alpha_{1}>0$ in the regression for a particular characteristic implies that the old firm characteristic is positively related to the new firm characteristic in the overall turnover sample, whereas $\beta_{1}>0$ implies that there is a positive relationship even outside the same industry and size decile groups.

Table 4 reports the coefficient estimates of Equations (12) and (13). In column (1) of Table 4 we report the coefficient estimates for $\alpha_{1}$, and in column (4), those for $\beta_{1}$; in columns (5) and (6), we report the coefficient estimates for $\beta_{2}$ and $\beta_{3}$, respectively. The results in column (1) reveal that a wide range of firm characteristics are relevant both economically and statistically for manager-firm matching. In tests not reported in the table, we repeated the exercise by randomly matching a new firm with an old firm and creating a sample of randomly matched firms. We created 500 such samples and repeated the regressions of Table 4 for each of the samples. None of the average estimated coefficients on the new firm characteristics were statistically different from zero.

To interpret the economic significance of some of the associations in Table 4, it is useful to have a benchmark. It is intuitive that the new and old firms would show some degree of sorting with respect to firm size: the "skill" required to manage large firms are presumably quite different than those required for small firms. ${ }^{22}$ Thus, the coefficient $\alpha_{1}$ when the old firm's size is regressed on the new firm's size can provide a benchmark. In Panel A, we first report the regression results for two measures of firm size: the log of market value and the log of book value of assets. The results in column (1) show that a $1 \%$ higher firm size for the new firm is

\footnotetext{
${ }^{22}$ The competitive assignment models maintain that more talented managers are assigned to larger firms. As argued above, it is reasonable to expect, based on these models, that the new and old firms will sort on size.
} 
associated, on average, with a $0.35 \%$ to $0.43 \%$ higher firm size for the old firm. We now discuss some of the other categories of firm characteristics in Panels B through E.

(i) Operating Characteristics: Among the operational characteristics, a 1 percentage point higher operating return on assets (OROA) for a new firm is on average associated with 0.2 percentage point higher OROA for the old firm from which the manager is hired. Within this category, intangibles as a proportion of total assets, goodwill as a proportion of total assets, and discretionary accruals over total assets involve even stronger associations between new and old firms.

(ii) Growth Prospects: Among variables related to growth prospects, several key variables exhibit strong associations. These are Tobin's Q, R\&D over assets, capital expenditures scaled by plant, property and equipment (CAPEX), and acquisitions scaled by assets. For example, a 1 percentage point higher CAPEX for a new firm is, on average, associated with a 0.2 percentage point higher CAPEX of the old firm from which the manager is hired.

(iii) Financial and Organizational Structure: Variables that are significant in the regressions are dividends over earnings, book leverage, cash holdings scaled by plant, property and equipment, and sales over assets. All exhibit economically strong associations for old and new firms. For example, a 1 percentage point higher book leverage for a new firm is associated with a 0.19 percentage point higher book leverage for the old firm from which the manager is hired. Sales over assets is a measure of vertical integration in a company. ${ }^{23} \mathrm{~A} 1$ percentage point higher value for vertical integration for a new firm, on average, is associated with a 0.34 percentage point higher value for the old firm from which the manager is hired.

(iv) Stock Market Characteristics: Variables that are associated with significant $\alpha_{1}$ coefficients in this category are idiosyncratic risk, beta, the ratio of market risk to total risk, turnover, trading volume, and the book-to-market ratio. Again, the effects are economically significant. For

\footnotetext{
${ }^{23}$ A firm that produces most of its inputs in-house would have a lower ratio of sales to assets. See Banerjee, Dasgupta and Kim (2008) for further discussion.
} 
example, if the beta of the new firm is higher by 1 , that of the old firm is, on average, higher by 0.25 .

The coefficient $\beta_{1}$ indicates whether these associations between new and old firm characteristics exist when the new and old firms are from different industries or size groups. We find that most do. Thus, these associations are not a consequence of new firms recruiting managers from firms in the same industry or from firms of similar size. The exceptions are two operating characteristics (cash flow over assets and OROA); one investment characteristic (acquisitions over assets); two financial characteristics (cash holding over assets and leverage), and two stock market characteristics (idiosyncratic risk and the book-to-market). Table 5 provides a summary of the firm-specific variables that have significant $\alpha_{1}$ and $\beta_{1}$ coefficients. ${ }^{24}$

So far we have documented robust evidence that there is a range of firm characteristics that is relevant for manager-firm matching. This set of variables allows us to evaluate, among all the turnover cases, the relative quality of a match. In Section 4, we form a measure of match quality and use it to examine the impact of match quality on the stock market announcement effect of a manager's appointment, the length of the manager's tenure, and the manager's compensation in the new firm.

\subsection{How Segmented is the Market for CEOs?}

Given our strong results of firm-manager fit on multiple dimensions, some questions naturally arise. For example, what if a new firm were to randomly pick a different manager? How likely is it that it would pick a manager whose fit would be worse than that with the manager it actually hires? These questions speak to how segmented the managerial labor market is and are examined in this section.

\footnotetext{
${ }^{24}$ Several managerial compensation variables also exhibit significant associations. We do not report them here as they are not "pure" firm characteristics.
} 
For each new firm, we randomly select a pseudo old firm, and calculate the DRD for each characteristic as well as the ADRD. However, now, unlike in Table 3 (where we examine the sample average DRDs), we fix the new firm and pick the pseudo old firm 1000 times, and each time, obtain the DRD for each characteristic as well as the ADRD over all characteristics. Next, we find the percentile positions of the DRD and the ADRD for the actual new and old firm pair in the resulting distributions. In the final step, we find the median percentile position for all pairs in the actual sample.

The results are reported in Table 6. The row labeled "All variables combined" corresponds to the ADRD over all characteristics. Column (1) reports the sample median percentile position of this decile distance, which is $10.3 \%$. Note that if the old and the new firms were randomly assigned, we would expect an average percentile position of $50 \%$. One way of understanding the $10.3 \%$ figure is the following: if the new firm were to randomly pick another firm to find its manager, it would only have a $10.3 \%$ chance of improving the fit, and an $89.7 \%$ change of worsening it. In contrast, under random assignment, it would have an equal chance of improving or worsening the fit. Thus, the odds ratio of improving the fit relative to random assignment of $1 / 9$ or 0.117 can be regarded as our measure of market segmentation. ${ }^{25}$ Evidently, the market is highly segmented.

As argued above, it is possible that the old and new firms are primarily matched by size, and the segmentation might simply reflect the effect of firm size, consistent with the assignment models of Terviö (2008) and Gabaix and Landier (2008). The next number in column (2) strongly rejects this possibility. Even when the pseudo old firm is chosen from the same size decile as the actual firm, the sample average percentile position of the average decile rank is $18.5 \%$, or an odds ratio of 0.23 . When the pseudo old firm is picked from the same industry as the actual old firm, the average percentile position is $17.5 \%$ (in column (3)), and the relative odds ratio is 0.21 . Overall, these results provide strong evidence of market segmentation that

\footnotetext{
${ }^{25}$ The odds ratio is $(10.5 \% / 89.5 \%) /(50 \% / 50 \%)=0.117$.
} 
goes beyond what might be expected on the basis of the size-talent assignment models or a preference for recruiting managers from particular industries.

\section{Match Quality}

In this section, we form a measure of match quality of a manager with the new firm and evaluate how match quality may affect shareholder wealth, tenure of the new executive, and his/her compensation.

We construct our measure of match quality based on a parsimonious set of 7 "match relevant" variables that have significant $\alpha_{1}$ coefficients in Equation (12). They are Tobin's Q, acquisitions over assets, sales over assets, share turnover, beta, the ratio of systematic risk to total risk $\left(\mathrm{R}^{2}\right)$, and the book-to-market ratio. To be conservative, in this list we do not include any of the characteristics relevant for operating performance or financial structure, which arguably could be more affected by the quality of a manager's fit with the old firm and thus may not be good candidates for the construction of a mismatch measure.

For each of these variables, we create an indicator that takes a value of 1 if the absolute rank difference is at least one standard deviation from the mean of all of the event firms, and 0 otherwise. The "mismatch score" is the sum of the 7 indicators.

As discussed in Section 2, this inverse measure of match quality with the new firm can be given a clean interpretation only if the manager is a good fit with the old firm to begin with. Otherwise, the firm characteristics of the old firm would be a poor proxy for the manager's attributes, and less distance between the new and the old firm could reflect a poor fit at the new firm as well. We assume that the manager is a good fit with the old firm if that firm's buy-andhold stock returns for the 3 years prior to the turnover exceeds that for the corresponding industry. Thus, we focus on the subsample for which this condition holds. For purposes of 
comparison, we also present results for the subsample in which the buy-and-hold return is below the industry median. ${ }^{26}$

\subsection{Match Quality and Wealth Effect of Managerial Moves}

We first examine whether, when the news that a manager joins a company is announced, the better the firm-manager match, the more positive the market reaction (Hypothesis 2 ). ${ }^{27} \mathrm{We}$ estimate Equation (14) in which the dependent variable is the cumulative abnormal return from one day before to one day after event day, (the day of announcement of the appointment news). The control variables include natural logarithm of market capitalization and leverage. All these variables are measured as of the year before the turnover year.

The results are reported in the first two columns of Table $7 .{ }^{28}$ Each explanatory variable is interacted with two indicator variables, corresponding to above industry median stock returns for the old firm in the prior three years in the upper panel, and below industry median stock returns in the prior three years in the lower panel. The mismatch score in the upper panel captures poor fit of the manager with the new firm. Consistent with our hypothesis, in the upper panel in column (1), the mismatch score has a negative coefficient, significant at the $1 \%$ level. In other words, when the manager has a good fit with the prior company and the new firm has similar characteristics to those of the old firm, the appointment of the manager has a more positive wealth effect. In contrast, for the below-industry-median buy-and-hold subsample for which we do not have a clear prediction for the coefficient of the mismatch score, the variable has no significant effect.

\footnotetext{
${ }^{26}$ If a lack of fit at the old firm affects performance variables, such as the ROA, it is possible that greater mismatch (in terms of distance between the new and the old firm characteristic) is associated with poor stock returns at the old firm. This is one reason that these variables are excluded from our mismatch measure.

${ }^{27}$ Pan (2010) constructs a measure of match quality based on a structural estimation, and finds that match quality is positively related to appointment announcement return, firm performance and tenure length.

${ }^{28}$ Note that the number of observations in the combined subsamples in the regressions in columns (1) and (2) of Table 7 falls to $64 \%$ of the turnover sample. This is mainly because the construction of the mismatch score requires the availability of all 7 characteristics, which causes data loss.
} 
In column (2), we add two indicator variables. "Industry Mismatch" takes a value of 1 if the firms are from different Fama-French industries, and zero otherwise; "Size Mismatch" takes a value of 1 if the firms are not from the same or adjacent size deciles, and zero otherwise. Neither variable is significant, indicating that, conditional on other firm characteristics, the market does not associate recruitment from firms that are dissimilar in size, or from other industries, with wealth losses.

\subsection{Match Quality and Length of Tenure}

We examine to what extent match quality is related to managerial tenure in the new firm (Hypothesis 3). Specifically, we hypothesize that the better the firm-manager match, the longer the manager's tenure. We estimate Equation (14) using the Cox hazard model. ${ }^{29}$

The results are reported in columns (5) and (6) of Table 7. We control for the length of the manager's prior tenure in the old firm, as well as the firm and industry stock returns for the new firm in the year prior to the appointment. Some managers may be changing jobs quickly, and past tenure length is intended to control for this effect. Similarly, tenure at the new firm may be affected by the industry conditions or the firm's performance that the manager inherits. As it turns out, none of these variables is significant.

For the above-industry median buy-and-hold subsample (upper panel), the mismatch variable has a positive effect (significant at $1 \%$ level), indicating that the manager is more likely to leave the firm if the match quality is worse. In the upper panel, the "Industry Mismatch" indicator has a positive coefficient significant at the 5\% level, and the "Size Mismatch" indicator also has a positive coefficient that is marginally insignificant at the $10 \%$ level. The coefficient of Mismatch is insignificant in the lower panel.

\footnotetext{
${ }^{29}$ We exclude cases in which the manager's departure is caused by the new firm's exit from the sample, which result in further loss of valid observations. For these results, we also control for the industry median stock return of the previous year as well as the firm's own stock return, since performance could be related to turnover. We do not cluster by year as STATA indicates singularity of the variance-covariance matrix.
} 


\subsection{Match Quality and Managerial Compensation}

We now investigate how match quality affects managerial compensation (Hypothesis 4). We control for size (logarithm of market value) and industry and year fixed effects as in Gabaix and Landier (2008).

The results are reported in columns (3) and (4) of Table 7. The dependent variable is natural logarithm of total pay (TDC1 in ExecuComp) in the (full) year after the appointment at the new firm. Consistent with our hypothesis, the mismatch score has a negative coefficient (significant at 5\% level) on the manager's total pay in the new firm in the above-industry median subsample in the upper panel. The mismatch variable is insignificant in the lower panel. As expected, firm size has a positive effect in both panels.

Overall, the results reported in Table 7 are strongly supportive of the hypothesis that firm-manager fit is relevant for firm value, managerial compensation and duration of tenure.

\section{Fit and Style}

Since firm-manager fit is likely to be imperfect, the question arises as to whether managers can change firm characteristics, and alternatively, whether the firm environment can shape managerial attributes. Clearly, some firm characteristics, such as those related to operational activities or those that reflect firm performance, can change when fit is imperfect. ${ }^{30}$ Managers can also "learn" and adapt to different firm environments, and thus managerial attributes can change when fit is less than perfect. Put differently, the fit between a manager and a firm can evolve over time.

Since managerial attributes are difficult to measure, it is not easy to document how managerial attributes evolve. However, the literature (Bertrand and Schoar (2003), Malmendier and Tate (2005), Graham, Li and Qiu, forthcoming) has recognized that managerial attributes

\footnotetext{
${ }^{30}$ It is for this reason that we leave our operational characteristics from our fit measure discussed in the previous section.
} 
influence firm characteristics. Bertrand and Schoar (2003) consider a sample of managerial turnovers and run regressions on a range of firm-specific variables by including managerspecific fixed effects. They show that these managerial fixed effects have incremental explanatory power for a wide range of firm characteristics, which they refer to as managerial style. $^{31}$

How does fit relate to style? Bertrand and Schoar (2003) comment: “....there is no such thing as a random allocation of top executives to firms. Therefore, we are not hoping [in this section] to estimate the causal effect of managers on firm practices. Instead, our objective is more modest. We want to assess whether there is any evidence that firm policies systematically change with the identity of the top managers in these firms" (Bertrand and Schoar (2003), page 1180 , italics ours).

The main finding in this paper is that firm characteristics are very similar in the two firms hiring the same manager even during periods that are outside the manager's tenure. While this is strong evidence of fit, if style is related to managerial attributes, our results do not preclude style. However, style effects are difficult to identify if firms are always able to achieve very good fit, since then one manager in charge of the firm is very similar to another. As a result, firm policies would not change systematically even when the identity of the manager changes.

We propose a test that can potentially disentangle the effect of style from that of fit. We argue that Bertrand and Schoar's (2003) premise that "firm policies [will] systematically change with the identity of the top managers" is more likely to be observed if the fit between the new firm and its manager is worse. The "style" hypothesis thus would predict that the larger the gap between a particular characteristic of the old and the new firm prior to the turnover, implying a worse fit with respect to that characteristic, the more will the new firm's characteristic change after the turnover under the influence of the manager. Not only that, the change will be

\footnotetext{
${ }^{31}$ In a recent paper, Fee, Hadlock and Pierce (2011) examine CEO replacements due to exogenous reasons (deaths, health reasons, and retirements that are not forced). They find no evidence of changes to firm policy or performance as new managers step in. In contrast, there are large changes following forced turnovers.
} 
directional: the new firm characteristic will change more in the direction of the old firm characteristic as the fit worsens, and managerial style has more impact.

As noted previously, the gap between an old and new firm characteristic is a reliable (inverse) measure of fit between the manager and the new firm only if the manager is also a good fit at the old firm. Thus, as before, to identify lack of fit, we interact the gap between an old and new firm characteristic with the past three year buy and hold return of the old firm. ${ }^{32}$ This motivates the following estimation strategy:

$$
X_{\text {post }}^{\text {new }}-X_{\text {pre }}^{\text {new }}=a_{0}+a_{1}\left(X_{\text {pre }}^{\text {new }}-X_{\text {pre }}^{\text {old }}\right)+a_{2}\left(X_{\text {pre }}^{\text {new }}-X_{\text {pre }}^{\text {old }}\right) * I_{\text {high return }}+a_{3} X_{p r e}^{\text {new }}+\text { Controls }+e,
$$

where the indicator variable $\mathrm{I}_{\text {high return }}$ takes a value of 1 if the three year buy and hold return in the old firm is above industry median, indicating that the manager was a good fit at the old firm. The style hypothesis then implies that we should expect $a_{1}+a_{2}$ to be negative. ${ }^{33}$

Note that the above specification is very similar to the standard model of estimating mean-reversion, with $X_{\text {pre }}^{\text {old }}$ replacing the long-run mean. Since we know from our previous results that the old and new firm characteristics are correlated, the old firm's X may contain information about the new firm's mean (provided that the manager is a good fit in the old firm). Thus, a negative coefficient for $a_{1}+a_{2}$ may simply reflect mean reversion of the new firm's $X$. To see whether this possibility can arise in the data, we simulate two series, which we call $X^{\text {old }}$ and $X^{\text {new }}$. The mean of $X^{\text {old }}$ is assumed to be 0.2 times the mean of $X^{\text {new }}$, plus a random term. Both series are assumed to follow an AR(1) process with a mean-reversion parameter of 0.5. We pick 100 pairs of means, and for each pair generate 1000 observations of $X^{\text {old }}$ and

\footnotetext{
${ }^{32}$ Here, we are agnostic as to whether the pre-turnover characteristic is the outcome of a good fit with the previous manager or is influenced by that manager.

${ }^{33}$ It is possible that a firm intentionally seeks a manager who fits poorly in terms of its existing characteristics because the board anticipates a change in the firm's environment (that is exogenous to the manager), and the new manager is a better fit in the new firm environment. However, this interpretation is inconsistent with our earlier finding that lack of fit around the turnover has negative consequences for shareholder wealth and managerial tenure.
} 
$X^{\text {new }}(\mathrm{t}=1, \ldots, 1000)$. For each pair of $X^{\text {old }}$ and $X^{\text {new }}$ series, we then arbitrarily choose some $\mathrm{t}$ and compute the change in the five-year average of $X^{\text {new }}$ before and after $\mathrm{t}$ (that is, $X_{\text {post }}^{\text {new }}-X_{\text {pre }}^{\text {new }}$ ). We regress this change on the difference of the five year average of $X^{\text {new }}$ and $X^{\text {old }}$ prior to $\mathrm{t}$ $\left(X_{\text {pre }}^{\text {new }}-X_{\text {pre }}^{\text {old }}\right)$, and the five year average value of $X^{\text {new }}$ prior to $\mathrm{t}\left(X_{\text {pre }}^{\text {new }}\right)$. The coefficient of $X_{\text {pre }}^{\text {new }}-X_{\text {pre }}^{\text {old }}$ is negative and significant, consistent with mean reversion.

To ensure that our attempts at identifying style effects do not simply pick up mean reversion, we implement a "difference-in-difference" approach. That is, we compare the postturnover impact of the old firm characteristics with that during periods when there is not a turnover. In other words, we use the level of $a_{1}+a_{2}$ during "normal" times as a benchmark. Thus we have the following model:

$$
\begin{aligned}
& X_{\text {post }}^{\text {new }}-X_{\text {pre }}^{\text {new }}=a_{0}+a_{1}\left(X_{\text {pre }}^{\text {new }}-X_{\text {pre }}^{\text {old }}\right)+a_{2}\left(X_{\text {pre }}^{\text {new }}-X_{\text {pre }}^{\text {old }}\right) * I_{\text {high return }}+a_{3} X_{\text {pre }}^{\text {new }}+\text { Controls }+e, \\
& X_{\text {post }}^{\text {new' }}-X_{\text {pre }}^{\text {new' }}=a_{0}^{\prime}+a_{1}^{\prime}\left(X_{\text {pre }}^{\text {new' }}-X_{\text {pre }}^{\text {old }}\right)+a_{3}^{\prime} X_{\text {pre }}^{\text {new' }}+\text { Controls }+e^{\prime}, \quad(17)
\end{aligned}
$$

where in Equation (16) the pre- and post- periods are defined relative to t, the turnover year, while in Equation (17), the pre-and-post variables for the new firm are defined relative to t-6, i.e., six years prior to the turnover year t. Each equation is applied to one cross-section of data. If style matters, we expect $a_{1}+a_{2}$ to be significantly more negative than $a_{1}$. As in earlier tests, pre- and post-X are all five year average values of X. $I_{\text {high return }}$ is an indicator variable for threeyear buy and hold returns at the old firm being above the industry median. "Controls" include the high return indicator and the five year average value of the log of market value of the new firm.

We estimate equations (16)-(17) in nested form, that is, we combine the two equations by creating an indicator variable $I_{\text {turnover }}$ indicating whether "pre" and "post" refer to the turnover 
year $t$, or year $t-6$. We then interact this indicator variable with $\left(X_{\text {pre }}^{\text {new }}-X_{\text {pre }}^{\text {old }}\right)$ and $\left(X_{\text {pre }}^{\text {new }}-X_{\text {pre }}^{\text {old }}\right) * I_{\text {high return }}$. More specifically, we use the below model:

$$
\begin{aligned}
X_{\text {post }}^{\text {new }}-X_{\text {pre }}^{\text {new }}= & a_{0}+a_{1}^{\prime}\left(X_{\text {pre }}^{\text {new }}-X_{\text {pre }}^{\text {old }}\right)+b_{1}\left(X_{\text {pre }}^{\text {new }}-X_{\text {pre }}^{\text {old }}\right) * I_{\text {turnover }} \\
& +b_{2}\left(X_{\text {pre }}^{\text {new }}-X_{\text {pre }}^{\text {old }}\right) * I_{\text {high return }} * I_{\text {turnover }}+a_{3}^{\prime} X_{\text {pre }}^{\text {new }}+\text { Controls }+e,
\end{aligned}
$$

We expect $b_{1}+b_{2}$ to be significantly negative. In Table 8 , we report the regression results for which $b_{1}+b_{2}$ is negative. ${ }^{34}$ It turns out $b_{1}+b_{2}$ is significantly negative for intangibles, advertising expenditures, goodwill, acquisitions, beta, illiquidity, and the book-to-market ratio.

In tests not reported in the Table, we further split $X_{p r e}^{\text {new }}-X_{\text {pre }}^{\text {old }}$ into positive and negative values. For goodwill and acquisitions, $b_{1}+b_{2}$ is significantly negative irrespective of the sign of $X_{\text {pre }}^{\text {new }}-X_{p r e}^{\text {old }}$, while intangibles and illiquidity are negatively significant for negative values of $X_{p r e}^{\text {new }}-X_{p r e}^{\text {old }}$ and negative but marginally insignificant for positive values. For Beta, $b_{1}+b_{2}$ is negatively significant only for negative values of the difference, whereas for advertisement, $b_{1}+$ $b_{2}$ is negatively significant only for positive vales of the difference.

These results suggest that acquisition activity is one of the major manifestations of managerial style, and managers who previously managed firms exposed to more systematic risk tend to increase the systematic risk of the new firms they move to. Similarly, managers who previously managed "growth" firms (low book-to-market) tend to move new firms in the same direction. Stock liquidity in new firms tends to improve when they bring in managers from firms that are more liquid (we have consistent evidence from the share turnover regression, although for this variable, $b_{1}+b_{2}$ is not significant overall).

\footnotetext{
${ }^{34}$ We do not report the estimates of $a_{1}^{\prime}$ in Table 8 . In 9 out of 32 regressions, this coefficient has a negative sign significant at least at the 5\% level; in 16 regressions, the coefficient is negative and the t-statistic is above 1.4. The coefficient is positive in 5 regressions, but only one is marginally significant.
} 
Other than share turnover, a few other variables that do not have significant values for $b_{1}+b_{2}$ for the overall sample have significant effects either for positive values or negative values of $X_{\text {pre }}^{\text {new }}-X_{\text {pre }}^{\text {old }}$. ROA and OROA both have negative significant coefficients (at 5\% and $10 \%$ levels, respectively) for positive values of $X_{p r e}^{\text {new }}-X_{\text {pre }}^{\text {old }}$. This suggests that when managers at firms with weaker operating performance (but above industry median stock returns) move to firms with better performance, the effect is to weaken the operating performance of the latter. Cash holding also has a negative significant coefficient when $X_{p r e}^{\text {new }}-X_{\text {pre }}^{\text {old }}$ is positive. The ratio of systematic risk to total risk, similar to beta, has a significant coefficient only for negative values of $X_{\text {pre }}^{\text {new }}-X_{\text {pre }}^{\text {old }}$. Interestingly, for capital expenditure, we find that $b_{1}+b_{2}$ is negative and significant for positive values of $X_{\text {pre }}^{\text {new }}-X_{\text {pre }}^{\text {old }}$ but positive and significant for negative values of $X_{p r e}^{\text {new }}-X_{p r e}^{\text {old }}$, suggesting that capital expenditure on average decreases at the new firm.

Overall, these results suggest the presence of managerial style effects. It is interesting to note that several of the variables that appear to be affected due to misfit belong to our list of match-relevant variables and the "mismatch" measure, e.g., acquisitions, beta, and the book-tomarket ratio (turnover and the ratio of market to total risk also feature for negative values of $X_{p r e}^{\text {new }}-X_{\text {pre }}^{\text {old }}$. This is exactly what we should expect if managerial attributes that match with these characteristics are considered important.

\section{Conclusion}

In recent assignment models, equilibrium entails positive assortative matching between firms and managers based on firm size and managerial talent. Managerial "ability" or "talent" is seen in these models as essentially a one-dimensional attribute over which all firms have the same preference ordering (i.e., all firms prefer a more talented manager). A closely related notion is that "general" management skills have become more important in recent decades and 
these skills are readily portable from one firm to another. Some have argued that the escalation in top management pay is a direct consequence of improvements in managerial mobility and improvement in managers' outside options due to the greater importance of general management skills.

In contrast, in this paper, we find strong evidence for the notion that assignment depends on fit between firms and managers along multiple dimensions, which implies that firms with different characteristics value managerial attributes differently. This suggests that competition for managers may be much more limited because firms with different characteristics need managers with specific attributes that fit these characteristics. In other words, the market for managerial talent is much more segmented than generally assumed. How multi-dimensional matching or fit affects equilibrium assignment and the allocative efficiency of managerial talent should be major issues for future research. Recent papers by Edmans and Gabaix (2011) and Eisfeldt and Kuhnen (2010) represent important steps in this direction. 


\section{References}

Allgood, S. and K. A. Farrell, 2003, The Match between CEO and Firm, Journal of Business 76, 317-341.

Amihud, Y., 2002 Illiquidity and Stock Returns: Cross-Section and Time-Series Effects, Journal of Financial Markets 5, 31-56

Bandiera, O., L. Guiso, A. Prat, and R. Sadun, 2011, Matching Firms, Managers, and Incentives, NBER Working Paper No. 16691.

Banerjee, S., S. Dasgupta and Y. Kim, 2008, Buyer-Supplier Relationships and the Stakeholder Theory of Capital Structure, Journal of Finance 63 (5), 2507-2552.

Bennedsen, M., F. Pérez-González, and D. Wolfenzon, 2008, Do CEOs Matter? NYU Working Paper No. FIN-06-032

Bertrand, M., A. Schoar, 2003, Managing with Style: The Effect of Managers on Firm Policies, Quarterly Journal of Economics 118, 1169-1208.

Brennan, M. J., T. Chordia and A. Subrahmanyam, 1998, Alternative Factor Specifications, Security Characteristics and the Cross-Section of Expected Stock Returns, Journal of Financial Economics 49, 345-373.

Chang, Y., S. Dasgupta, and G. Hillary, 2010, CEO Ability, Pay, and Firm Performance, Management Science 56, 1633-1652.

Edmans, A. and X. Gabaix, 2011, The Effect of Risk on the CEO Market, Review of Financial Studies 24, 2822-2863.

Eisfeldt, A. L., and C. M. Kuhnen, 2010, CEO Turnover in a Competitive Assignment Framework, SSRN Working paper.

Falato, A., D. Li, and T. Milbourn, 2011, To Each According to His Ability? CEO Pay and the Market for CEOs, Working Paper.

Fama, E.F. and K.R. French, 1997, Industry Costs of Equity, Journal of Financial Economics 43, 153-193.

Fee, C. E., C. J. Hadlock, and J. R. Pierce, 2011, Managers Who Lack Style: Evidence from Exogenous CEO Changes, SSRN Working paper.

Frydman, C., 2007, Rising Through the Ranks: The Evolution of the Market for Corporate Executives, 1936-2003, Working paper.

Frydman, C., and R.E. Saks, 2010, Executive Compensation: A New View from a Long-Term Perspective, 1936-2005, Review of Financial Studies 23, 2099-2138.

Gabaix, X., A. Landier, 2008, Why Has CEO Pay Increased So Much? Quarterly Journal of Economics 123 49-100.

Graham, J. R., C. R. Harvey, and M. Puri, 2010, Managerial Attitudes and Corporate Actions, SSRN 
Working paper.

Graham, John, Si Li and Jiaping Qiu, 2011, Managerial Attributes and Executive Compensation, forthcoming, Review of Financial Studies.

Groysberg, B., A. N. McLean, and N. Nohria, May 2006, Are Leaders Portable? Harvard Business Review 84, 92-100.

Kaplan, S., M. Klebanov, and M. Sorensen, 2012, Which CEO Characteristics and Abilities Matter? Journal of Finance, forthcoming.

Kothari, S.P.., A. J. Leone and C. E. Wasley, 2005, Performance Matched Discretionary Accrual Measures, Journal of Accounting and Economics 39, 163-197.

Malmendier, U, and G. Tate, 2005, CEO Overconfidence and Corporate Investment, Journal of Finance 60, 2661-2700.

Murphy, K. J. and J. Zábojník, 2004, CEO Pay and Appointments: A Market-Based Explanation for Recent Trends, American Economic Review 94(2), 192-196.

Murphy, K. J. and J. Zábojník, 2007, Managerial Capital and the Market for CEOs, SSRN Working paper.

Nguyen, B.D., K.M. Nielsen, 2010, What Death Can Tell: Are Executives Paid for Their Contributions to Firm Value? AFA 2011 Denver Meetings Paper.

Pan, Y., 2010, The Determinants and Impact of Executive-Firm Matches, SSRN Working Paper.

Rosen, S., 1974, Hedonic Prices and Implicit Markets: Product Differentiation in Pure Competition, Journal of Political Economy 82, 34-35.

Rosen, S., 1981, The Economics of Superstars, American Economic Review 71(5), 845-858.

Sattinger, M., 1979, Differential Rents and the Distribution of Earnings, Oxford Economic Papers 31, 60-71.

Sattinger, M., 1993, Assignment Models of the Distribution of Earnings, Journal of Economic Literature 31, 831-880.

Terviö, M., 2008, The Difference that CEOs Make: An Assignment Model Approach, American Economic Review 98(3), 642-668. 


\section{Appendix 1: Proof of Proposition 1}

The proof for $m>1$ is similar to that for $m=1$. Let us write condition (11) as

$$
(1-\alpha)\left(a_{1}^{i}\right)^{2}-\left(a_{1}^{i}-a_{1}^{j}\right)^{2}>-k
$$

where $k=\sum_{s=2}^{m}\left((1-\alpha)\left(a_{s}^{i}\right)^{2}-\left(a_{s}^{i}-a_{s}^{j}\right)^{2}\right)=\mu\left(a_{2}^{i}, \ldots, a_{m}^{i} ; a_{2}^{j}, \ldots, a_{m}^{j}\right)$.

Notice that given $a_{1}^{i}$, the function $(1-\alpha)\left(a_{1}^{i}\right)^{2}-\left(a_{1}^{i}-a_{1}^{j}\right)^{2}$ is concave and single peaked (see

Figure 1). Let $k\left(a_{1}^{i}\right)$ denote the highest value of this function. For given $a_{1}^{i}$ and $k \geq k\left(a_{1}^{i}\right)$, there is an interval $\left[a_{1}^{j^{*}}\left(a_{1}^{i}, k\right), a_{1}^{j^{* *}}\left(a_{1}^{i}, k\right)\right]$ such that $a_{1}^{j}$ must lie in this interval for condition (A1) to hold (see Figure 1). Thus, for given $a_{1}^{i}, a_{1}^{j}$ must lie in an interval $\left[a_{1}^{j^{*}}\left(a_{1}^{i}\right), a_{1}^{j^{* *}}\left(a_{1}^{i}\right)\right]$ where

$$
a_{1}^{j^{*}}=\inf _{k}\left\{a_{1}^{j^{*}}\left(a_{1}^{i}, k\right): k \geq-k\left(a_{1}^{i}\right)\right\}
$$

and

$$
a_{1}^{j^{* *}}=\sup _{k}\left\{a_{1}^{j^{*}}\left(a_{1}^{i}, k\right): k \geq-k\left(a_{1}^{i}\right)\right\}
$$

It is easy to show that both $a_{1}^{j^{*}}$ and $a_{1}^{j^{* *}}$ are non-decreasing in $a_{1}^{i}$ (see Figure 1). Thus, the

conditional distribution $P\left(a_{1}^{j} \mid a_{1}^{i}\right)=\frac{F\left(a_{1}^{j}\right)-F\left(a_{1}^{j^{*}}\left(a_{1}^{i}\right)\right)}{F\left(a_{1}^{j^{* *}}\left(a_{1}^{i}\right)-F\left(a_{1}^{j^{*}}\left(a_{1}^{i}\right)\right)\right.}$ is decreasing in $a_{1}^{i}$ and the proof follows. 


\section{Appendix 2: Construction of Variables}

1. Acquisitions

Acquisitions (aqc) over the beginning-of-period book value of assets (lagged at)

$=$ aqc/lagged at

2. Advertising Expenditures

Advertising expenditures (xad) over the beginning-of-period total assets (lagged at)

$=\mathrm{xad} /$ lagged at

3. Assets (Book Assets)

$=$ at

4. Beta

The estimated slope coefficient of the following regression:

$\mathrm{R}_{\mathrm{j}, \mathrm{t}}-\mathrm{R}_{\mathrm{f}, \mathrm{t}}=$ intercept $_{\mathrm{j}}+$ slope $_{\mathrm{j}} *\left(\mathrm{R}_{\mathrm{m}, \mathrm{t}}-\mathrm{R}_{\mathrm{f}, \mathrm{t}}\right)+\mathrm{e}_{\mathrm{j}, \mathrm{t}}$

5. Book-to-market Ratio

$=\mathrm{ceq} /(\mathrm{prc} * \mathrm{csho})$

where

ceq is the book value of common equity;

prc is the closing share price of the fiscal year;

csho is the common share outstanding.

6. Business-Segment Herfindahl-Hirschman Index:

$\sum_{s}\left(\frac{\text { sales }}{\sum_{s} \text { sales }}\right)^{2}$ where s indexes business segments

7. Capital Expenditures

Capital expenditures (capx) over net property, plant, and equipment at the beginning of the fiscal year (lagged ppent)

$=$ capx/lagged ppent

8. Cash Holdings

Cash and short-term investment (che) over net property, plant, and equipment at the beginning of the fiscal year (lagged ppent)

$=$ che/lagged ppent

9. Cash Flow

The sum of earnings before extraordinary items (ib) and depreciation (dp) over net property, plant, and equipment at the beginning of the fiscal year (lagged ppent)

$=(\mathrm{ib}+\mathrm{dp}) /$ lagged ppent

10. Discretionary Accruals (Kothari, Leone and Wasley, 2005)

The discretionary accruals is the residual value of the following regression.

$\mathrm{TA}_{\mathrm{it}}=\mathrm{a}_{0}+\mathrm{a}_{1}\left(1 /\right.$ ASSETS $\left._{\mathrm{it}-1}\right)+\mathrm{a}_{2}\left(\Delta\right.$ SALES $\left._{\mathrm{it}}\right)+\mathrm{a}_{3}$ PPE $_{\mathrm{it}}+\mathrm{a}_{4} \operatorname{OIBDP}_{\mathrm{it}-1}+\mathrm{e}_{\mathrm{it}}(\mathrm{A} 3)$

where $\mathrm{i}$ indexes firms; $\mathrm{t}$ indexes years; $\mathrm{TA}=(\Delta \mathrm{Data} 4-\Delta \mathrm{Data} 1-\triangle \mathrm{Data} 5+$

$\Delta$ Data34 - Data14)/Lagged Data $6 ; \Delta$ SALES $=\Delta$ Data12, scaled by Lagged Data 6;

PPE $=$ Data8 scaled by Lagged Data 6; OIBDP is the operating income before

depreciation scaled by total assets. The regression is run cross-sectionally each year using all firm-year observations in the same two-digit SIC code.

- data4; ACT: current assets 
- data1; CHE: cash and short-term investments

- data5; LCT: current liabilities

- data34; DLC: debt in current liabilities

- data14; DP: depreciation and amortization

- data12; SALE: net sales

- data8; PPENT: net PPE

- data6; AT: total assets

11. Dividends

Dividends over earnings

$=(\mathrm{dvc}+\mathrm{dvp}) / \mathrm{oibdp}$

where

$\mathrm{dvc}$ is dividends for common equity;

$\mathrm{dvp}$ is dividends for preferred shares;

oibdp is operating income before depreciation.

12. Excess Return Over Market

The annual stock return minus the annual market return

13. Geographical Segment Herfindahl-Hirschman Index:

$\sum_{s}\left(\frac{\text { sales }}{\sum_{s} \text { sales }}\right)^{2}$ where s indexes geographical segments

14. Goodwill

Goodwill (gdwl) over total assets (at)

$=\mathrm{gdwl} / \mathrm{at}$

15. Idiosyncratic Risk

Residual sum of squares from the following regression:

$$
\mathrm{R}_{\mathrm{j}, \mathrm{t}}-\mathrm{R}_{\mathrm{f}, \mathrm{t}}=\text { intercept }_{\mathrm{j}}+\operatorname{slope}_{\mathrm{j}}^{*}\left(\mathrm{R}_{\mathrm{m}, \mathrm{t}}-\mathrm{R}_{\mathrm{f}, \mathrm{t}}\right)+\mathrm{e}_{\mathrm{j}, \mathrm{t}}
$$

16. Illiquidity:

$$
\frac{1}{D_{j}} \sum_{d=1}^{\boldsymbol{D}_{j}} \frac{\left|\boldsymbol{R}_{\boldsymbol{j}, d}\right|}{\boldsymbol{V O L}_{\boldsymbol{j}, \boldsymbol{d}}}
$$

where $R_{j, d}$ is the daily return on stock $j$ on day $d, V_{j, d}$ is the daily trading volume for stock $j$ on day $d$, and $D_{j}$ is the number of days with data in a year (Amihud (2002)).

17. Intangibles/Assets:

Intangible assets (intan) over total assets (at)

$=$ intan/at

18. Interest Coverage

Earnings before depreciation, interest, and tax (oibdp) over interest expenses (xint)

$=$ oibdp/xint

19. Leverage

Long-term debt (dltt) plus debt in current liabilities (dlc) over long-term debt plus debt in current liabilities plus the book value of common equity (ceq)

$=(\mathrm{dltt}+\mathrm{dlc}) /(\mathrm{dltt}+\mathrm{dlc}+\mathrm{ceq})$ 
20. Market Value

The book value of assets (at) plus the market value of common equity (prc $\times$ csho) less the sum of the book value of common equity (ceq) and balance sheet deferred taxes

(txdb)

$=\mathrm{at}+$ pre $\times$ csho $-(\mathrm{ceq}+\mathrm{txdb})$

21. Non-Discretionary Accruals (Kothari, Leone and Wasley, 2005)

The non-discretionary accruals is the predicted value of the following regression.

$\mathrm{TA}_{\mathrm{it}}=\mathrm{a}_{0}+\mathrm{a}_{1}\left(1 /\right.$ ASSETS $\left._{\mathrm{it}-1}\right)+\mathrm{a}_{2}\left(\Delta\right.$ SALES $\left._{\mathrm{it}}\right)+\mathrm{a}_{3}$ PPE $_{\mathrm{it}}+\mathrm{a}_{4}$ OIBDP $_{\mathrm{it}-1}+\mathrm{e}_{\mathrm{it}}(\mathrm{A} 3)$ where $\mathrm{i}$ indexes firms; $\mathrm{t}$ indexes years; $\mathrm{TA}=(\Delta \mathrm{Data} 4-\Delta \mathrm{Data} 1-\Delta \mathrm{Data} 5+$

$\Delta$ Data34 - Data14) $/$ Lagged Data $6 ; \Delta$ SALES $=\Delta$ Data12, scaled by Lagged Data 6 ; PPE $=$ Data8 scaled by Lagged Data 6; OIBDP is the operating income before depreciation scaled by total assets. The regression is run cross-sectionally each year using all firm-year observations in the same two-digit SIC code.

- data4; ACT: current assets

- data1; CHE: cash and short-term investments

- data5; LCT: current liabilities

- data34; DLC: debt in current liabilities

- data14; DP: depreciation and amortization

- data12; SALE: net sales

- data8; PPENT: net PPE

- data6; AT: total assets

22. Price-to-earnings Ratio

$=$ prc/epsfx

where

prc is the closing share price of the fiscal year;

epsfx is earnings per share (diluted) excluding extraordinary items

23. ROA

Income before extraordinary items (ib) over the beginning-of-period total assets (lagged at)

$=\mathrm{ib} /$ lagged at

24. R\&D Expenditures

R\&D expenditures (xrd) over the beginning-of-period total assets (lagged at)

$=\mathrm{xrd} /$ lagged at

25. Operating ROA

Operating net cash flow (oancf) over the beginning-of-period total assets (lagged at)

$=$ oancf $/$ lagged at

26. Sales over Assets (Vertical Integration)

$=$ sale/lagged at

27. Selling, General, and Administrative Expense

Selling, general and administrative expense (xsga) over the beginning-of-period sales

(lagged sale)

$=\mathrm{xsga} /$ lagged sale

28. Systematic Risk/Total Risk $\left(\mathrm{R}^{2}\right)$

$\mathrm{R}^{2}$ from the following regression:

$\mathrm{R}_{\mathrm{j}, \mathrm{t}}-\mathrm{R}_{\mathrm{f}, \mathrm{t}}=$ intercept $_{\mathrm{j}}+$ slope $_{\mathrm{j}} *\left(\mathrm{R}_{\mathrm{m}, \mathrm{t}}-\mathrm{R}_{\mathrm{f}, \mathrm{t}}\right)+\mathrm{e}_{\mathrm{j}, \mathrm{t}}$ 
29. Trading Volume

The average of daily dollar trading volume over a year (Brennan, Chordia, and Subrahmanyam (1998)).

30. Tobin's Q

Market Value divided by Assets. Both Market Value and Assets are defined above.

31. Turnover

The average of daily share turnover over a year, where the daily share turnover is calculated as the number of shares traded in a day divided by the number of shares outstanding as of the end of that day. 


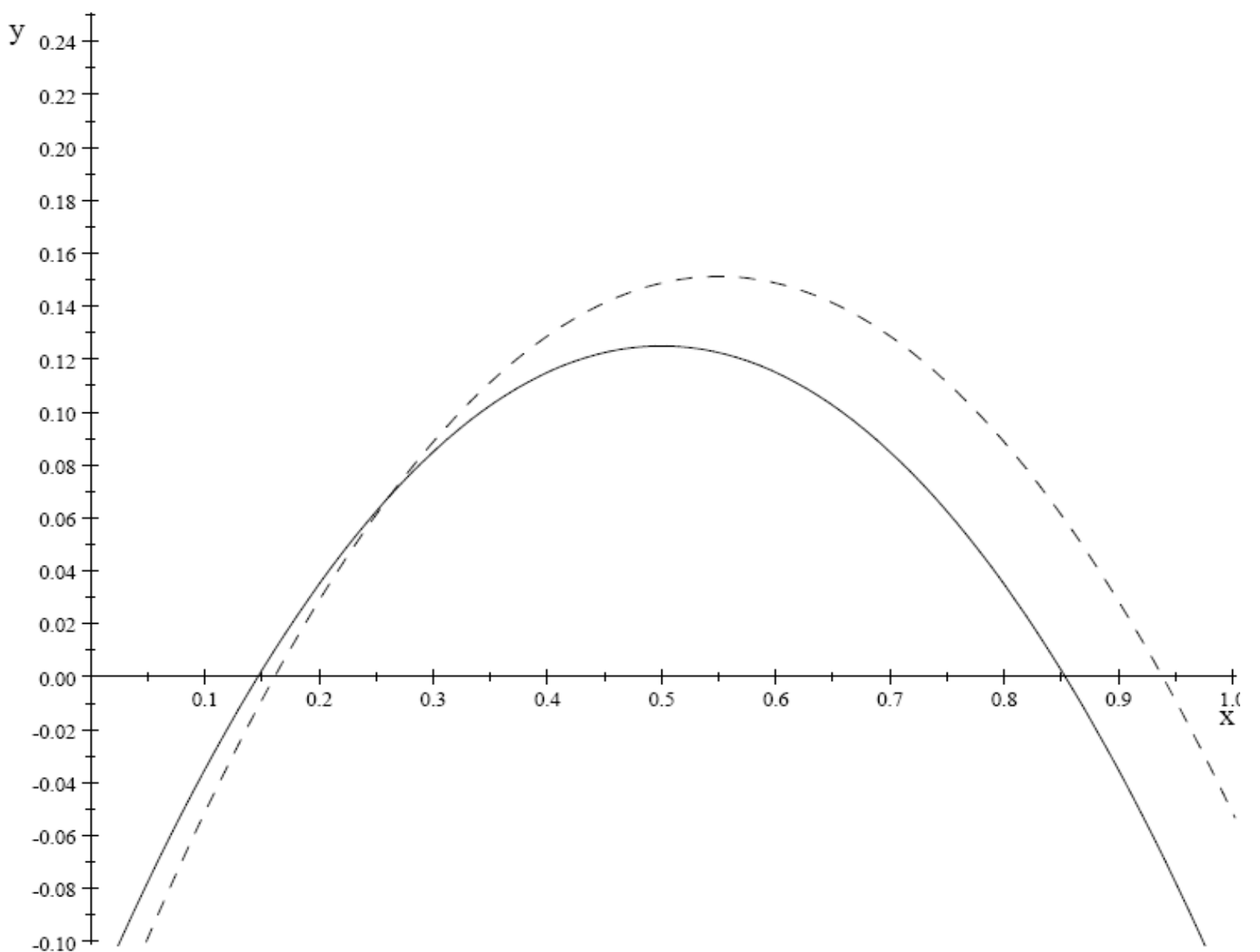

Figure 1: Plot of $(1-\alpha)\left(a_{1}^{i}\right)^{2}-\left(a_{1}^{i}-a_{1}^{j}\right)^{2}$ against $a_{1}^{j}$. Solid Line : $a_{1}^{i}=0.5$, Dashed Line : $a_{1}^{i}=0.55$ 
Table 1. Sample Statistics

"New firm" refers to the firm the manager joins, and "old firm" refers to the firm the manager leaves. Panel A reports the median and mean ratio of the new firm's market value/book assets (in 2000 dollars), as of the year prior to the appointment, to the old firm's market value/book assets (in 2000 dollars), as of the year prior to the departure; the number of observations; the percent of CEO-to-CEO moves, non-CEO-to-CEO moves and CEO-to-non-CEO moves in the sample. Panel B presents the means and medians of firm characteristics for three groups of firms for the period 1987-2009 that are examined in the paper. The construction of these characteristics is given in Appendix 2. Superscripts ***,** and * indicate that the statistic is significantly different from that of the new firm at $1 \%, 5 \%$ and $10 \%$, respectively. Superscripts a, b and c indicate that the statistic is significantly different from that of the largest 1500 in terms of market value of Compustat/CRSP at $1 \%, 5 \%$ and $10 \%$, respectively.

Panel A: New vs. Old Size

\begin{tabular}{lcccccc}
\hline & \multicolumn{2}{c}{$\begin{array}{c}\text { CEO-to-CEO } \\
\text { Moves }\end{array}$} & \multicolumn{2}{c}{$\begin{array}{c}\text { Non-CEO-to-CEO } \\
\text { Moves }\end{array}$} & \multicolumn{2}{c}{$\begin{array}{c}\text { CEO-to-Non-CEO } \\
\text { Moves }\end{array}$} \\
& Median & Mean & Median & Mean & Median & Mean \\
Market Value: New Firm/Old Firm & 1.79 & 5.46 & 0.2 & 0.56 & 2.71 & 7.86 \\
Book Assets: New Firm/Old Firm & 2.02 & 6.06 & 0.19 & 0.82 & 1.49 & 7.05 \\
& Frequency & Percent & Frequency & Percent & Frequency & Percent \\
Number of Observations & 171 & 0.44 & 188 & 0.49 & 27 & 0.07 \\
\hline
\end{tabular}




\begin{tabular}{|c|c|c|c|c|c|c|}
\hline & \multicolumn{2}{|c|}{ Old Firms } & \multicolumn{2}{|c|}{ New Firms } & \multicolumn{2}{|c|}{$\begin{array}{c}\text { Largest } 1500 \\
\text { in Compustat/CRSP }\end{array}$} \\
\hline & Mean & Median & Mean & Median & Mean & Median \\
\hline \multicolumn{7}{|c|}{ Size } \\
\hline Book Assets (in 2000 dollars in millions) & $15209^{* * *, a}$ & $2321^{* * *, a}$ & $8164^{\mathrm{a}}$ & $1353^{\mathrm{a}}$ & 28153 & 11565 \\
\hline Market Value (in 2000 dollars in millions) & $18541^{* * *, a}$ & $3153^{* * *, a}$ & $12016^{\mathrm{a}}$ & $1847^{\mathrm{a}}$ & 42784 & 22807 \\
\hline \multicolumn{7}{|c|}{ Operational Characteristics } \\
\hline Intangibles & $0.11^{*}$ & $0.05^{\mathrm{a}}$ & 0.11 & $0.05^{\mathrm{a}}$ & 0.11 & 0.04 \\
\hline Goodwill & $0.09^{* * *}, \mathrm{a}$ & $0.04^{* * *, a}$ & $0.09^{\mathrm{a}}$ & $0.03^{\mathrm{a}}$ & 0.06 & 0.01 \\
\hline Non-discretionary Accruals & $0.02^{* * *}$ & $0.01^{\mathrm{a}}$ & $0.01^{\mathrm{b}}$ & $0.01^{\mathrm{a}}$ & 0.01 & 0.01 \\
\hline Discretionary Accruals & -0.01 & $-0.01^{\mathrm{c}}$ & -0.01 & -0.01 & -0.01 & -0.00 \\
\hline Selling, General, and Administrative Expenses & $0.32^{* * *, a}$ & $0.26^{\mathrm{a}}$ & $0.34^{\mathrm{a}}$ & $0.26^{\mathrm{a}}$ & 0.26 & 0.22 \\
\hline Advertising Expenditures & $0.04^{* * *, a}$ & 0.02 & $0.05^{\mathrm{a}}$ & 0.02 & 0.04 & 0.02 \\
\hline Cash Flow & $0.45^{\mathrm{a}}$ & $0.34^{* *}, \mathrm{a}$ & $0.45^{\mathrm{a}}$ & 0.33 & 0.62 & 0.33 \\
\hline Operating Return on Assets & $0.10^{* * *, a}$ & $0.10^{* * *}$ & $0.08^{\mathrm{a}}$ & $0.09^{\mathrm{a}}$ & 0.11 & 0.10 \\
\hline Return on Assets & $0.04^{* * *, a}$ & $0.05^{* * *}$ & $0.03^{\mathrm{a}}$ & $0.04^{\mathrm{a}}$ & 0.06 & 0.05 \\
\hline \multicolumn{7}{|c|}{ Growth Prospects and Investment Activity } \\
\hline Growth Prospects (Tobin's Q) & 1.92 & $1.45^{\mathrm{a}}$ & $1.89^{\mathrm{c}}$ & $1.47^{\mathrm{a}}$ & 1.93 & 1.38 \\
\hline Capital Expenditures & $0.32^{\mathrm{a}}$ & $0.21^{* *, a}$ & $0.33^{\mathrm{a}}$ & $0.20^{\mathrm{b}}$ & 0.26 & 0.20 \\
\hline R\&D Expenditures & $0.08^{\mathrm{a}}$ & $0.04^{\mathrm{a}}$ & $0.08^{\mathrm{a}}$ & $0.04^{\mathrm{a}}$ & 0.05 & 0.03 \\
\hline Acquisitions & 0.03 & $0.00^{* * *}$ & 0.03 & $0.00^{\mathrm{a}}$ & 0.03 & 0.00 \\
\hline \multicolumn{7}{|c|}{ Financial and Organizational Structure } \\
\hline Leverage & $0.40^{* * *, a}$ & $0.37^{* * *, a}$ & $0.38^{\mathrm{a}}$ & $0.35^{\mathrm{a}}$ & 0.43 & 0.41 \\
\hline Interest Coverage & $24.95^{*, a}$ & $7.22^{* * *}$ & $27.91^{\mathrm{a}}$ & $6.64^{\mathrm{b}}$ & 21.75 & 7.01 \\
\hline Cash Holdings & $2.25^{* * *, a}$ & $0.29^{* * *, a}$ & $3.24^{\mathrm{a}}$ & $0.38^{\mathrm{a}}$ & 1.93 & 0.22 \\
\hline Dividends & $0.10^{\mathrm{a}}$ & $0.06^{* * *, a}$ & $0.10^{\mathrm{a}}$ & $0.03^{\mathrm{a}}$ & 0.14 & 0.11 \\
\hline Business-Segment Herfindahl-Hirschman Index & $0.77^{\mathrm{a}}$ & $1.00^{* *, a}$ & $0.78^{\mathrm{a}}$ & $1.00^{\mathrm{a}}$ & 0.68 & 0.67 \\
\hline Geographical Segment Herfindahl-Hirschman Index & $0.69^{* * *, a}$ & $0.66^{* * *}$ & $0.71^{\mathrm{a}}$ & $0.72^{\mathrm{a}}$ & 0.67 & 0.66 \\
\hline Vertical Integration (Sales over Assets) & $1.10^{* * *, a}$ & $0.95^{* *, a}$ & $1.04^{\mathrm{a}}$ & $0.92^{\mathrm{a}}$ & 0.82 & 0.68 \\
\hline \multicolumn{7}{|c|}{ Stock Market Characteristics } \\
\hline Excess Return over Market & 0.00 & 0.00 & 0.00 & 0.00 & 0.00 & 0.00 \\
\hline Beta & $1.14^{\mathrm{a}}$ & $1.05^{\mathrm{a}}$ & $1.16^{\mathrm{a}}$ & $1.05^{\mathrm{a}}$ & 1.04 & 0.96 \\
\hline Idiosyncratic Risk & $0.18^{* * *, a}$ & $0.10^{* * *, a}$ & $0.20^{\mathrm{a}}$ & $0.11^{\mathrm{a}}$ & 0.10 & 0.06 \\
\hline Systematic Risk/Total Risk $\left(\mathrm{R}^{2}\right)$ & $0.22^{* * *, a}$ & $0.19^{* * *, a}$ & $0.21^{\mathrm{a}}$ & $0.17^{\mathrm{a}}$ & 0.24 & 0.22 \\
\hline Illiquidity & $10 \mathrm{e}-7^{* *}, \mathrm{c}$ & $6 \mathrm{e}-8^{* * *, a}$ & $1 e-6^{a}$ & $9 e-8^{a}$ & $8 e-7$ & $4 e-8$ \\
\hline Turnover & $0.01^{*, a}$ & $0.00^{* * *, a}$ & $0.01^{\mathrm{a}}$ & $0.00^{\mathrm{a}}$ & 0.01 & 0.00 \\
\hline Trading Volume (in thousands) & $1554^{* * *, a}$ & $357^{* * *}, \mathrm{a}$ & $1067^{\mathrm{a}}$ & $274^{\mathrm{a}}$ & 2551 & 499 \\
\hline Book-to-market Ratio & 0.50 & 0.43 & 0.51 & $0.44^{\mathrm{b}}$ & 0.50 & 0.42 \\
\hline Price-to-earnings Ratio & $16.62^{*, \mathrm{a}}$ & $15.47^{\mathrm{aa}}$ & $15.40^{\mathrm{a}}$ & $15.12^{\mathrm{a}}$ & 20.09 & 16.13 \\
\hline
\end{tabular}


Table 2. Summary Statistics of Decile Rank Distance (DRD) Between Characteristics of Old and New Firms

Each year, for firms in Compustat/CRSP, we sort each firm characteristic into deciles and assign decile ranks $(1=$ largest and $10=$ smallest $)$. We then calculate the absolute difference of the rank of the characteristic of the old firm as of the year after the move and that of the new firm as of the year before the move (DRD). We also calculate the average of the absolute difference in rank of all 29 variables (ADRD). For the latter, missing variables are ignored in computing the average. The table reports the mean, 25,50 and 75 percentiles of the absolute difference in ranks.

\begin{tabular}{lcccc}
\hline Match-relevant Variable & mean & p25 & p50 & p75 \\
\hline \hline ADRA (all variables combined) & 2.28 & 1.72 & 2.14 & 2.72
\end{tabular}

Decile Rank Distance (DRD)

\begin{tabular}{|c|c|c|c|c|}
\hline \multicolumn{5}{|c|}{ Panel A: Size } \\
\hline Market Value & 1.27 & 0 & 1 & 2 \\
\hline Book Assets & 1.46 & 0 & 1 & 2 \\
\hline \multicolumn{5}{|c|}{ Panel B: Operational Characteristics } \\
\hline Intangibles & 1.89 & 1 & 2 & 3 \\
\hline Goodwill & 1.62 & 1 & 1 & 2 \\
\hline Non-discretionary Accruals & 2.72 & 1 & 2 & 4 \\
\hline Discretionary Accruals & 2.63 & 1 & 2 & 4 \\
\hline Selling, General, and Administrative Expenses & 1.92 & 1 & 2 & 3 \\
\hline Advertising Expenditures & 2.11 & 1 & 2 & 3 \\
\hline Cash Flow & 2.39 & 1 & 2 & 3 \\
\hline Return on Assets & 2.46 & 1 & 2 & 4 \\
\hline Operating Return on Assets & 2.42 & 1 & 2 & 4 \\
\hline \multicolumn{5}{|c|}{ Panel C: Growth Prospects and Investment Activities } \\
\hline Tobin's Q & 2.39 & 1 & 2 & 4 \\
\hline Capital Expenditures & 2.30 & 1 & 2 & 3 \\
\hline R\&D Expenditures & 1.38 & 0 & 1 & 2 \\
\hline Acquisitions & 1.09 & 0 & 1 & 2 \\
\hline \multicolumn{5}{|c|}{ Panel D: Financial and Organizational Structure } \\
\hline Leverage & 2.77 & 1 & 1 & 4 \\
\hline Interest Coverage & 2.42 & 1 & 2 & 4 \\
\hline Cash Holdings & 2.18 & 1 & 2 & 3 \\
\hline Dividends & 1.30 & 0 & 1 & 2 \\
\hline Business Segment Herfindahl-Hirschman Index & 2.21 & 1 & 2 & 4 \\
\hline Geographical Segment Herfindahl-Hirschman Index & 1.85 & 1 & 2 & 3 \\
\hline Vertical Integration (Sales over Assets) & 1.83 & 1 & 1 & 3 \\
\hline \multicolumn{5}{|c|}{ Panel E: Stock Market Characteristics } \\
\hline Excess Return over Market & 2.99 & 1 & 3 & 5 \\
\hline Beta & 2.59 & 1 & 2 & 4 \\
\hline Idiosyncratic Risk & 2.31 & 1 & 2 & 3 \\
\hline Systematic Risk/Total Risk & 2.75 & 1 & 2 & 4 \\
\hline Illiquidity & 1.47 & 0 & 1 & 2 \\
\hline Trading Volume & 1.67 & 0 & 1 & 3 \\
\hline Turnover & 2.08 & 1 & 2 & 3 \\
\hline Book-to-market Ratio & 2.59 & 1 & 2 & 4 \\
\hline Price-to-earnings Ratio & 2.51 & 1 & 2 & 4 \\
\hline
\end{tabular}


Table 3. Sample Median/Mean DRDs and Random Assignment Benchmarks

This table shows the percentage of cases in 1000 simulations that the sample median/mean decile rank distance (DRD) between an old and new firm characteristic, and the sample median/mean ADRD over all non-missing characteristics, for the actual sample is not larger than the corresponding one for samples generated via random assignment. We proceed in the following steps. Step 1: For each new firm in our actual sample, we obtain a "pseudo old firm" by randomly drawing a firm from Compustat/CRSP universe in the same firm year. This generates a new sample (a "random sample" with each new firm randomly assigned to a pseudo old firm). When we consider a particular characteristic, we require that the randomly drawn firm has non-missing data for that variable. Step 2: For each pair of a new firm and the corresponding pseudo old firm, we calculate the DRD for each firm characteristic, and also the ADRD, as explained in Table 2. Step 3: We calculate the sample median/mean DRD and ADRD for the random sample. Step 4: We do Steps 1-4 1000 times. Step 5: We calculate the sample median/mean DRD for each variable, and the sample median/mean ADRD, for the actual sample. Step 6: We rank the 1001 medians/means $(=1000$ medians $/$ means from the 1000 random samples +1 median/mean from the actual sample). Column (1) reports the percentage of cases the median/mean ADRD and the median/mean DRDs for individual characteristics for the actual sample are not larger than those for the random assignment samples. In columns (2)-(3), we follow the same procedure, except that in column (2) [3], when we randomly draw a pseudo old firm, we require that this firm be in the same (size decile) [Fama-French industry] as the actual old firm.

\begin{tabular}{llll}
\hline Drawn from the same year & Yes & Yes & Yes \\
Drawn from the same size decile as the actual old firm & No & Yes & No \\
Drawn from the same industry as the actual old firm & No & No & Yes \\
\hline \hline
\end{tabular}

(1) (2) (3)

Panel A: Using Median Decile Rank Distance (DRD)

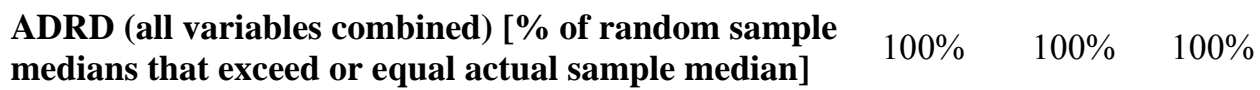

Median DRD for Individual Variables [\% of random sample medians that exceed or equal actual sample median]

Leverage

Excess Return over Market

$97 \% \quad 100 \% \quad 71 \%$

Advertising Expenditures

$99 \% \quad 96 \% \quad 100 \%$

All other individual variables

$100 \% \quad 98 \% \quad 100 \%$

$100 \% \quad 100 \% \quad 100 \%$ 
Table 3. Sample Median/Mean DRDs and Random Assignment Benchmarks (continued)

\begin{tabular}{llll}
\hline Drawn from the same year & Yes & Yes & Yes \\
Drawn from the same size decile as the actual old firm & No & Yes & No \\
Drawn from the same industry as the actual old firm & No & No & Yes \\
\hline \hline
\end{tabular}

(1) (2) (3)

Panel B: Using Mean Decile Rank Distance (DRD)

ADRD (all variables combined) [\% of random sample means that exceed or equal actual sample mean] $\quad 100 \% \quad 100 \% \quad 100 \%$

Mean DRD for Individual Variables [\% of random sample means that exceed or equal actual sample mean]

Operational Characteristics

Intangibles

Non-discretionary Accruals

$100 \% \quad 88 \% \quad 99 \%$

Discretionary Accruals

$100 \% \quad 96 \% \quad 100 \%$

Operating Return on Assets

$100 \% \quad 99 \% \quad 100 \%$

Return on Assets

$100 \% \quad 98 \% \quad 98 \%$

$100 \% \quad 100 \% \quad 97 \%$

\section{Growth Prospects and Investment Activity}

Growth Prospects (Tobin's Q)

$100 \% \quad 99 \% \quad 100 \%$

Capital Expenditures

$100 \% \quad 97 \% \quad 100 \%$

Acquisitions

$100 \% \quad 90 \% \quad 96 \%$

Financial and Organizational Structure

Leverage

$100 \% \quad 97 \% \quad 100 \%$

Cash Holdings

$100 \% \quad 99 \% \quad 100 \%$

Dividends

$100 \% \quad 97 \% \quad 100 \%$

Geographical Segment Herfindahl-Hirschman Index

$100 \% \quad 96 \% \quad 100 \%$

Business Segment Herfindahl-Hirschman Index

$100 \% \quad 97 \% \quad 90 \%$

Stock Market Characteristics

Excess Return over Market

$100 \% \quad 96 \% \quad 53 \%$

Beta

Systematic Risk/Total Risk $\left(\mathrm{R}^{2}\right)$

$100 \% \quad 100 \% \quad 99 \%$

Book-to-market Ratio

$100 \% \quad 100 \% \quad 94 \%$

Price-to-earnings Ratio

$100 \% \quad 99 \% \quad 99 \%$

$100 \% \quad 99 \% \quad 95 \%$ 
Table 4. Regression Results on the Relationship Between Characteristics of the "New" and "Old" Firms

This table reports the regression coefficient estimates of the following models:

$$
\begin{aligned}
& \mathrm{X}_{\text {post }}^{\text {old }}=\alpha_{0}+\alpha_{1} \mathrm{X}_{\text {pre }}^{\text {new }}+\mathrm{e}_{\text {post }}^{\text {old }} \\
& \mathrm{X}_{\text {post }}^{\text {old }}=\beta 0+\beta 1 \mathrm{X}_{\text {pre }}^{\text {new }}+\beta_{2} \mathrm{X}_{\text {pre }}^{\text {new }}{ }^{*} \text { IndustryMatch }+\beta_{3} \mathrm{X}_{\text {pre }}^{\text {new }} * \text { SizeMatch }+\mathrm{e}_{\text {post }}^{\text {old }}
\end{aligned}
$$

where $X^{\text {old }}$ post is the average value of $X$ of the old firm over the 5 years after the manager leaves the old firm. $X^{\text {new }}$ pre is the average value of $X$ of the new firm over the 5 years before the manager joins the new firm. IndustryMatch takes a value of 1 if the new firm's 48 Fama-French industry classification is the same as the old firm's, and 0 otherwise. SizeMatch takes a value of 1 if the absolute difference in the size decile rank between the new firm and the old firm is smaller than or equal to $1 . \mathrm{t}$ statistics are based on robust standard errors using the Huber-White sandwich estimators. ***, ** and * denote $1 \%, 5 \%$ and $10 \%$ level of significance, respectively. \# indicates $10 \%$ significance level for a two-sided test. $\mathrm{R}^{2}$ and $\mathrm{N}$ (the number of observations) are those

\begin{tabular}{|c|c|c|c|c|c|c|}
\hline & $\alpha_{1}$ & $\mathbf{N}$ & $\mathbf{R}^{2}$ & $\beta_{1}$ & $\beta_{2}$ & $\beta_{3}$ \\
\hline \multicolumn{7}{|c|}{ Panel A: Size } \\
\hline Log(Market Value) & $0.435^{* * *}$ & 162 & 0.18 & $0.323^{* * *}$ & -0.028 & $0.111^{* * *}$ \\
\hline Log(Book Assets) & $0.353^{* * *}$ & 219 & 0.17 & $0.337^{* * *}$ & -0.003 & 0.034 \\
\hline \multicolumn{7}{|c|}{ Panel B: Operational Characteristics } \\
\hline Intangibles & $0.304^{* * *}$ & 190 & 0.07 & $0.407^{* * *}$ & $-0.474^{* * *}$ & -0.076 \\
\hline Goodwill & $0.304^{* * *}$ & 162 & 0.07 & $0.296^{* * *}$ & $-0.299^{*}$ & 0.091 \\
\hline Discretionary Accruals & $0.346^{* * *}$ & 179 & 0.04 & $0.293^{*}$ & -0.170 & 0.350 \\
\hline Cash Flow & $0.069^{*}$ & 204 & 0.00 & 0.042 & 0.031 & 0.012 \\
\hline Operating Return on Assets & $0.203^{* *}$ & 205 & 0.07 & 0.064 & $0.276^{* *}$ & -0.085 \\
\hline \multicolumn{7}{|c|}{ Panel C: Growth Prospects and Investment Activities } \\
\hline Growth Prospects (Tobin's Q) & $0.227^{* * *}$ & 162 & 0.06 & $0.210^{* *}$ & -0.092 & 0.076 \\
\hline R\&D Expenditures & $0.174^{*}$ & 114 & 0.13 & $0.193^{*}$ & -0.053 & 0.134 \\
\hline Capital Expenditures & $0.218^{*}$ & 199 & 0.14 & $0.261^{* * *}$ & -0.108 & -0.011 \\
\hline Acquisitions & $0.307^{*}$ & 189 & 0.04 & $0.554^{\#}$ & $-0.335^{* *}$ & -0.369 \\
\hline \multicolumn{7}{|c|}{ Panel D: Financial and Organizational Structure } \\
\hline Cash Holdings & $0.097^{* *}$ & 209 & 0.01 & $0.118^{\#}$ & -0.015 & -0.020 \\
\hline Leverage & $0.189^{* * *}$ & 216 & 0.04 & 0.104 & 0.097 & 0.076 \\
\hline Dividends & $0.234^{* * *}$ & 209 & 0.06 & $0.147^{*}$ & $0.229^{* *}$ & 0.047 \\
\hline Vertical Integration (Sales over Assets) & $0.343^{* * *}$ & 218 & 0.10 & $0.240^{* * *}$ & $0.241^{* *}$ & -0.022 \\
\hline \multicolumn{7}{|c|}{ Panel E: Stock Market Characteristics } \\
\hline Beta & $0.246^{* * *}$ & 189 & 0.08 & $0.312^{* * *}$ & -0.040 & -0.097 \\
\hline Idiosyncratic Risk & $0.151^{*}$ & 189 & 0.03 & 0.055 & $0.171^{\#}$ & 0.020 \\
\hline Market Risk/Total Risk $\left(\mathrm{R}^{2}\right)$ & $0.313^{* * *}$ & 189 & 0.06 & $0.342^{* * *}$ & -0.108 & 0.009 \\
\hline Turnover & $0.312^{* * *}$ & 189 & 0.09 & $0.209^{* *}$ & 0.125 & 0.146 \\
\hline Log(Trading Volume) & $0.449^{* * *}$ & 189 & 0.18 & $0.451^{* * *}$ & -0.018 & 0.008 \\
\hline Book-to-market Ratio & $0.182^{*}$ & 197 & 0.03 & $0.184^{\#}$ & 0.069 & -0.125 \\
\hline
\end{tabular}
of the model (1). 
Table 5. Summary of Main Results in Table 4: Variables Relevant for FirmManager Matching ("Match-Relevant Variables")

+ indicates a significant and positive estimated coefficient of $X^{\text {new }}$ pre in Table 4; a blank cell indicates an insignificant estimated coefficient of $X^{\text {new }}{ }_{\text {pre }}$.

Controlling for Industry Match and Size Match

NO $\left(\alpha_{1}\right)$

YES $\left(\beta_{1}\right)$

Panel A: Size

Market Value

Book Assets

Panel B: Operational Characteristics

Intangibles

$+\quad+$

Goodwill

Discretionary Accruals

$+\quad+$

Cash Flow

$+$

Operating Return on Assets

$\begin{array}{ll}+ & + \\ + & +\end{array}$

\section{Panel C: Growth Prospects and Investment Activities}

Growth Prospects (Tobin's Q)

R\&D Expenditures

Capital Expenditures

$\begin{array}{ll}+ & + \\ + & + \\ + & \\ + & \end{array}$

Acquisitions

Panel D: Financial and Organizational Structure

Cash Holdings

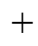

Leverage

Dividends

Vertical Integration (Sales over Assets)

Panel E: Stock Market Characteristics

Idiosyncratic Risk

Beta

Market Risk/Total Risk $\left(\mathrm{R}^{2}\right)$

Turnover

Trading Volume

Book-to-market Ratio

$\begin{array}{ll}+ & \\ + & + \\ + & + \\ + & + \\ + & + \\ + & \end{array}$




\section{Table 6. Segmentation in the CEO Talent Market}

This table provides evidence of market segmentation in the CEO talent market. The steps are as follows. We index a sample new and old firm pair by $i, i=1, \ldots,, \mathrm{N}$, and a firm characteristic by $X_{k}, k=1, \ldots, \mathrm{K}$. Step 1: For each new firm $i$ in our actual sample, we obtain a pseudo old firm by randomly drawing a firm from Compustat/CRSP universe in the same firm year. Step 2: We calculate the DRD for each firm characteristic $X_{k}$ between the new firm and the pseudo old firm, as well as the ADRD, as detailed in Table 2. Step 3: For each actual new firm $i$, we do Step 1 and Step 2 1000 times. Step 4: For each characteristic $X_{k}$, we rank the DRD for the 1001 pairs (=1000 randomly assigned pairs +1 actual pair) and obtain the rank of the actual sample pair $i$. We denote this rank by $R_{-} i, X_{k}$. We similarly obtain the rank of the ADRD for the actual sample pair $i$. Step 5: We repeat the above steps for all the remaining new firms $i=1, . ., \mathrm{N}$. Step 6: For each $X_{k}$, we calculate the median value of $R \_i, X_{k}$ over all sample pairs $i$. We also calculate the median of the ADRD rank over all $i$. These median ranks are shown in column (1). In columns (2)-(3), we follow the same procedure, except that in column (2) [3], when we randomly draw a pseudo old firm, we require that this firm is in the same (size decile) [Fama-French industry] as the actual old firm.

\begin{tabular}{lccc}
\hline Drawn from the same year & Yes & Yes & Yes \\
Drawn from the same size decile as the actual old firm & No & Yes & No \\
Drawn from the same industry as the actual old firm & No & No & Yes \\
\hline \hline & $(1)$ & $(2)$ & $(3)$ \\
Median ADRD Rank (all variables combined) & 103 & 185.5 & 175.5
\end{tabular}

Median DRD Ranks for Individual Firm Characteristics

\begin{tabular}{lccc}
\hline Acquisitions & 39 & 51 & 44 \\
Dividends & 97 & 76 & 163 \\
Illiquidity & 101 & 103 & 180.5 \\
R\&D Expenditures & 103 & 176 & 122 \\
Book Assets & 104 & 137 & 150.5 \\
Trading Volume & 104 & 123 & 239 \\
Vertical Integration (Sales over Assets) & 113 & 225.5 & 166 \\
Goodwill & 121.5 & 164.5 & 166.5 \\
Selling, General, and Administrative Expenses & 124 & 164 & 268 \\
Geographical Segment Herfindahl-Hirschman Index & 175 & 252 & 245 \\
Advertising Expenditures & 221 & 233 & 336 \\
Intangibles & 258 & 215 & 253.5 \\
Business Segment Herfindahl-Hirschman Index & 268 & 305 & 308 \\
Turnover & 274 & 219.5 & 232 \\
Cash Flow & 285 & 227 & 230 \\
\hline
\end{tabular}


Table 6 (continued)

\begin{tabular}{lccc}
\hline Drawn from the same year & Yes & Yes & Yes \\
Drawn from the same size decile as the actual old firm & No & Yes & No \\
Drawn from the same industry as the actual old firm & No & No & Yes \\
\hline \hline Idiosyncratic Risk & 292 & 233 & 233 \\
Operating ROA & 294 & 293.5 & 380 \\
Price-to-earnings Ratio & 295 & 250 & 336 \\
Cash Holdings & 295.5 & 328 & 296 \\
Interest Coverage & 296 & 265 & 351 \\
ROA & 296.5 & 304.5 & 308.5 \\
Growth Prospects (Tobin's Q) & 297.5 & 330.5 & 305 \\
Beta & 302 & 318 & 336 \\
Discretionary Accruals & 304 & 322.5 & 283 \\
Book-to-market Ratio & 304 & 339 & 343 \\
Capital Expenditures & 305 & 307 & 336.5 \\
Systematic Risk/Total Risk $\left(\mathrm{R}^{2}\right)$ & 310 & 307 & 324 \\
Leverage & 310.5 & 343 & 385.5 \\
Non-discretionary Accruals & 321 & 327 & 295 \\
Excess Return over Market & 326 & 343.5 & 380.5 \\
\hline
\end{tabular}


Table 7. Match Quality: Effects on Shareholder Wealth, Managerial Pay and Tenure

This table presents regression results on how the quality of the manager's match at the new firm affects the stock price reaction of the new firm to the appointment news, the managerial pay and tenure at the new firm. The dependent variable in columns (1) and (2) is the cumulative abnormal return from the day before to the day after the announcement day of the managerial appointment, and in columns (3) and (4) it is the natural logarithm of the manager's total pay in the year after the appointment year in the new firm. In columns (5) and (6), we estimate the departure rate at the new firm based on the Cox model, where we exclude cases in which the manager leaves the firm because the firm no longer exists. We create an indicator for the observations with high pre-departure 3-year stock return for the old firm (above the industry median) and another indicator for the observations with low pre-departure 3-year stock return for the old firm (below the industry median). We interact each explanatory variable separately with these two indicators. Mismatch is constructed as follows. We consider 7 "match-relevant" variables: Tobin's Q, acquisition, sales/assets, turnover, beta, systematic risk/total risk $\left(\mathrm{R}^{2}\right)$, and book-to-market ratio. For each of these variables, we create an indicator that takes a value of 1 if the decile rank distance between the new and the old firm is at least one standard deviation from the mean of all of the event firm pairs, and 0 otherwise. Mismatch is the sum of the 7 indicators. Industry Mismatch takes a value of 1 if the old and new firms are in different industries (based on Fama-French 48 industry classification), and 0 otherwise. Size Mismatch takes a value of 1 if the absolute rank difference in size between the old and new firms is larger than 1, and 0 otherwise. $\log$ (market value) is the natural logarithm of the market value of the new firm as of the year prior to the executive appointment. Leverage is long-term debt plus debt in current liabilities over long-term debt plus debt in current liabilities plus the book value of common equity of the new firm as of the year prior to the manager's appointment. Prior Tenure is the length of tenure (in days) of the manager in the old firm. Past Stock Return is the stock return of the new firm for the year prior to the manager's appointment. Industry Past Stock Return is the corresponding industry median of Past Stock Return. Industry and year fixed effects are included in columns (3)-(4). The table reports the estimated coefficients of the ordinary least squares linear regressions [in columns (1)-(4)] or the "hazard ratio" of the Cox regression [in columns (5)-(6)], corresponding absolute $t$ or $z$ statistics (in parentheses), based on robust standard errors for all columns, Adjusted $\mathrm{R}^{2}$ or Wald Chi Square, and the number of observations. ***, ** and * denote $1 \%, 5 \%$ and $10 \%$ level of significance, respectively. 


\begin{tabular}{|c|c|c|c|c|c|c|}
\hline \multirow[t]{2}{*}{ Dependent Variable: } & \multicolumn{2}{|c|}{ Appointment CAR } & \multicolumn{2}{|c|}{$\log$ (Total Pay) } & \multicolumn{2}{|c|}{ Tenure } \\
\hline & $(1)$ & $(2)$ & (3) & (4) & $(5)$ & $(6)$ \\
\hline \multicolumn{7}{|c|}{ High Pre-departure 3-year Stock Return for the Old Firm } \\
\hline \multirow[t]{2}{*}{ Intercept } & $0.076^{* *}$ & $0.078^{*}$ & $15.515^{* * *}$ & $15.682^{* * *}$ & & \\
\hline & $(2.03)$ & $(1.87)$ & $(4.22)$ & $(4.30)$ & & \\
\hline \multirow[t]{2}{*}{ Mismatch } & $-0.020^{* * *}$ & $-0.019^{* *}$ & $-0.255^{* *}$ & $-0.261^{* *}$ & $1.256^{* * *}$ & $1.317^{* * *}$ \\
\hline & $(2.66)$ & $(2.54)$ & $(2.00)$ & $(2.05)$ & $(3.50)$ & $(3.93)$ \\
\hline \multirow[t]{2}{*}{ Industry Mismatch } & & -0.016 & & 0.049 & & $0.634^{* *}$ \\
\hline & & $(0.91)$ & & $(0.26)$ & & $(1.98)$ \\
\hline \multirow[t]{2}{*}{ Size Mismatch } & & 0.008 & & 0.067 & & 1.373 \\
\hline & & $(0.47)$ & & $(0.35)$ & & $(1.57)$ \\
\hline \multirow[t]{2}{*}{$\log$ (Market Value) } & -0.005 & -0.005 & $0.359^{* * *}$ & $0.362^{* * *}$ & 1.021 & 1.029 \\
\hline & $(1.09)$ & $(1.01)$ & $(5.55)$ & $(5.16)$ & $(0.38)$ & $(0.53)$ \\
\hline \multirow[t]{2}{*}{ Leverage } & 0.050 & 0.052 & -0.157 & -0.182 & 0.978 & 0.973 \\
\hline & $(1.60)$ & $(1.63)$ & $(0.52)$ & $(0.62)$ & $(0.63)$ & $(0.72)$ \\
\hline \multirow[t]{2}{*}{ Prior Tenure } & & & & & 0.999 & 1.000 \\
\hline & & & & & $(1.28)$ & $(1.43)$ \\
\hline \multirow[t]{2}{*}{ Past Stock Return } & & & & & 1.025 & 1.084 \\
\hline & & & & & $(0.38)$ & $(0.96)$ \\
\hline \multirow[t]{2}{*}{ Industry Past Stock Return } & & & & & 0.597 & 0.526 \\
\hline & & & & & $(1.04)$ & $(1.31)$ \\
\hline \multicolumn{7}{|c|}{ Low Pre-departure 3-year Stock Return for the Old Firm } \\
\hline \multirow[t]{2}{*}{ Intercept } & -0.044 & -0.042 & & & 2.255 & 3.484 \\
\hline & $(1.54)$ & $(1.31)$ & & & $(0.72)$ & $(1.09)$ \\
\hline \multirow[t]{2}{*}{ Mismatch } & 0.009 & 0.009 & 0.137 & 0.108 & 1.034 & 1.050 \\
\hline & $(1.41)$ & $(1.35)$ & $(1.28)$ & $(1.01)$ & $(0.28)$ & $(0.42)$ \\
\hline \multirow[t]{2}{*}{ Industry Mismatch } & & -0.003 & & -0.422 & & 0.670 \\
\hline & & $(0.19)$ & & $(1.66)$ & & $(1.19)$ \\
\hline \multirow[t]{2}{*}{ Size Mismatch } & & 0.003 & & 0.130 & & 0.674 \\
\hline & & $(0.17)$ & & $(0.61)$ & & $(1.44)$ \\
\hline \multirow[t]{2}{*}{$\log$ (Market Value) } & 0.004 & 0.004 & $0.434^{* * *}$ & $0.452^{* * *}$ & 0.965 & 0.987 \\
\hline & $(1.22)$ & $(1.23)$ & $(4.49)$ & $(4.46)$ & $(0.40)$ & $(0.15)$ \\
\hline \multirow[t]{2}{*}{ Leverage } & 0.023 & 0.021 & $-0.690^{*}$ & $-0.838^{* *}$ & 0.796 & 0.660 \\
\hline & $(0.91)$ & $(0.82)$ & $(1.89)$ & $(2.25)$ & $(0.36)$ & $(0.58)$ \\
\hline \multirow[t]{2}{*}{ Prior Tenure } & & & & & 1.000 & 1.000 \\
\hline & & & & & $(0.34)$ & $(0.05)$ \\
\hline \multirow[t]{2}{*}{ Past Stock Return } & & & & & 0.909 & 0.933 \\
\hline & & & & & $(1.21)$ & $(1.21)$ \\
\hline \multirow[t]{2}{*}{ Industry Past Stock Return } & & & & & 0.618 & 0.502 \\
\hline & & & & & $(0.85)$ & $(1.15)$ \\
\hline Adjusted $R^{2}$ & 0.099 & 0.088 & 0.586 & 0.582 & & \\
\hline Wald Chi Square & & & & & $22.89^{* *}$ & $31.22^{* *}$ \\
\hline Number of Observations & 237 & 237 & 181 & 181 & 207 & 207 \\
\hline
\end{tabular}


Table 8. Testing for Style

This table reports the regression coefficient estimates for Equation (18) in the main body of the paper:

$$
\begin{aligned}
X_{\text {post }}^{\text {new }}-X_{\text {pre }}^{\text {new }}= & a_{0}^{\prime}+a_{1}^{\prime}\left(X_{\text {pre }}^{\text {new }}-X_{\text {pre }}^{\text {old }}\right)+b_{1}\left(X_{\text {pre }}^{\text {new }}-X_{\text {pre }}^{\text {old }}\right) * I_{\text {turnover }} \\
& +b_{2}\left(X_{\text {pre }}^{\text {new }}-X_{\text {pre }}^{\text {old }}\right) * I_{\text {high return }} * I_{\text {turnover }}+a_{3}^{\prime} X_{\text {pre }}^{\text {new }}+\text { Controls }+e,
\end{aligned}
$$

where $I_{\text {turnover }}$ equals one if pre- and post- are calculated based on the turnover year and zero if pre- and post- are calculated based on the non-turnover year t- 6 . Both pre- and post- are the five-year average values with respect to the reference year. The model is the nested form of Equations (16) and (17) in the paper. $I_{\text {high return }}$ is an indicator variable for three-year buy and hold returns at the old firm being above the industry median. Controls include the high return indicator and the five year average value of the log of market value of the new firm. $t$ statistics are based on robust standard errors using the Huber-White sandwich estimators. ${ }^{* * *}, * *$ and $*$ denote $1 \%, 5 \%$ and $10 \%$ level of significance, respectively. $\mathrm{N}$ is the

\begin{tabular}{|c|c|c|c|c|}
\hline & $\mathbf{b}_{1}$ & $\mathbf{b}_{1}+\mathbf{b}_{2}$ & $\mathbf{N}$ & $\mathbf{R}^{2}$ \\
\hline \multicolumn{5}{|c|}{ Panel A: Operational Characteristics } \\
\hline Intangibles & -0.082 & $-0.196^{* *}$ & 291 & 0.10 \\
\hline Goodwill & -0.074 & $-0.232^{* *}$ & 200 & 0.10 \\
\hline Advertising Expenditures & 0.045 & $-0.374^{* *}$ & 66 & 0.56 \\
\hline \multicolumn{5}{|c|}{ Panel B: Growth Prospects and Investment Activities } \\
\hline Acquisitions & -0.049 & $-0.292^{* * *}$ & 309 & 0.57 \\
\hline \multicolumn{5}{|c|}{ Panel E: Stock Market Characteristics } \\
\hline Beta & -0.058 & $-0.312^{* *}$ & 322 & 0.36 \\
\hline Illiquidity & $-1.00^{* * *}$ & $-1.717^{*}$ & 323 & 0.58 \\
\hline Book-to-market Ratio & 0.045 & $-0.305^{*}$ & 328 & 0.32 \\
\hline
\end{tabular}
number of observations used in the regression. 